\title{
Impact of Gas in Sodium Flow on the Temperature Variation of an LMFBR Rod Bundle
}

K. Marten, E. Baumgärtner, M. Khan, H. Hoffmann Institut für Reaktorbauelemente Projekt Schneller Brüter

\section{Kernforschungszentrum Karlsruhe}




\section{KERNFORSCHUNGSZENTRUM KARLSRUHE \\ Institut fir Reaktorbauelemente \\ Projekt Schneller Bruter}

KfK 325.3

IMPACT OF GAS IN SODIUM FLOW

ON THE TEMPERATURE VARIATION OF AN LMFBR ROD BUNDLE

K. Marten, E. Baumgärtner, M. Khan, H. Hoffmann

Kernforschungszentrum Karlsruhe GmbH, Karlsruhe 
Als Manuskript vervielfältigt

Für diesen Bericht behalten wir uns alle Rechte vor

Kernforschungszentrum Karlsruhe $\mathrm{GmbH}$

ISSN 0303-4003 
IMPACT OF GAS IN SODIUM FLOW ON THE TEMPERATURE VARIATION OF AN LMFBR ROD BUNDLE

\section{Abstract}

The impact of gas in sodium flow on the temperature variation of an LMFBR rod bundle was studied in two types of experiments:

- The gas fraction of the subchannels as well as the aas bubble spectra across the outlet of an unheated 61-rod bundle with wire spacers were measured in water/air flow. For uniform and non-uniform gas distribution at the bundle inlet, the determined averaged qas fractions across the subchannels at the bundle outlet were uniform and non-uniform, respectively. The measured bubble spectra show a dependency between the bubble frequencies, the contact times and the gas fractions of a subchannel.

- A model to compute the transient temperature distributions within a heated rod was supported by experiments in a sodium/ argon slug flow. The measurements show that the fluid and the rod temperature variations increase with increasing heat flux, gas fraction and contact time of a single bubble at the wall.

The knowledge of the averaged gas fractions in the subchannels allows to calculate for practical reasons the mean subchannel coolant and wall temperature rises, the knowledge of the contact time of a bubble at the wall allows to calculate the wall temperature variations due to the presence of gas in the sodium flow of an LMFBR. rod bundle.

\section{DIE AUSWIRKUNG VON GAS IN EINER NATRIUMSTROOMUNG AUF DIE TEMPERATUR-} VARIATIONEN IN EINEM STABBUNDEL FUR SCHNELLE BRUTREAKTOREN

\section{Zus ammenfassung}

Um die durch Gas in einer Natriumströmung in einem Stabbiindel bewirkten Temperaturvariationen bestimmen zu können, wurden zwei

Arten von Experimenten durchgeführt:

- Gasanteile und Blasenspektren der Unterkanäle am Austritt eines 61-Stabbiindels mit Wendeldrahtabstandshaltern wurden in vasser Luft-Strömung gemessen. Für gleichförmige und ungleichförmige Gasverteilunaen vor dem Bündel ergeben sich gemittelte Gasanteile in den Unterkanälen, deren Verteilungen am Bündelaustritt entsprechend gleichförmiq und ungleichförmig sind. Die gemessenen Blasenspektren zeigen einen Zusammenhang $z$ wischen Blasenfrequenz, Kontaktzeit und Gasanteil der Unterkanäle.

- Ein Rechenmodell fur transiente Temperaturverteilungen in beheizten Stäben wurde abgestützt durch Versuche in Natrium/ArgonStrömung. Die Messungen zeigen eine eindeutige Abhängigkeit der Stabtemperaturvariationen vom wärmefluß, Gasanteil und von der Kontaktzeit einer Einzelblase an der beheizten Stabwand.

Die Kenntnis der Gasverteilung erlaubt für oraktische Zwecke die Berechnung der durch die Anwesenheit von Gas in der Strömung bewirkten mittleren Kühlmittel- und Wandaufheizungen in einem von Flüsigmetall durchströmten Bündel, die Kenntnis der Kontaktzeiten der Blasen an der Wand $1 \ddot{3} \beta t$ die Berechnung der Temperaturschwankungen der wärmeabgebenden wände zu. 


\section{Content}

Abstract

1. Introduction

2. Experimental Determination of the Distribution of the Averaged Gas Fractions in the Subchannels 3

2.1 Test Section

2.2 Measuring Technique

2.3 Experimental Parameters

2.4 Results

3. Theoretical Considerations

3.1 Transferability of Water/Air Results to Sodium/Argon

3.2 Calculation Model Describing the Transient

Temperature Variations of a Cylindrical Rod

4. Experimetal Investigations of Temperature Variations 16

4.1 Test Section

4.2 Measuring Technique

4.3 Results

5. Summary and Conclusions

6. References

7. Nomenclature

Figures 


\section{INTRODUCTION}

Fuel, blanket and absorber elements of LMFBRs are characterized by high heat flux densities. As long as the heat removal is ensured by sodium flow, the temperatures and their distribution on the surfaces of these elements are solely determined by the conditions of single phase flow prevailing in the typical bundle geometries. If gas is assumed to be present in the coolant under non-nominal operating conditions, it must be transported via the core elements to the upper nlenum of the reactor /1/. Then the rod surface temperatures are determined by the conditions of two-phase, two-component flow. Some core elements of LMFBRs are equipped with helical wire spacers wrapped around each rod. This tyoe of saacer generates a swirl between the outmost row of rods and the shroud 12/. It may be assumed that this helical spacer type likewise influences the liquid/gas flow along the subassembly and it is therefor of great interest how this gas distribution in the liquid undergoes chanoes from the entrance to the outlet of the subassembly. Gas entrained in subassemblies has a double effect from both the thermo- and fluiddynamic points of view:

- The nominal sodium mass flow is reduced and, consequently, the averaged coolant temperature in the core element rises the more the hioher the gas fraction is, supposed that the thermal pover remains unchanged.

- The presence of gas slugs in the coolant channel diminishes the heat transfer between the rod surface and the coolant. In an extremely unfavorable case, the heat transfer surface may be isolated by gas. Then nearly adiabatic rod heat-up must be anticipated.

Both the enhancement of the average coolant temperatures in a subassembly and the rise of the local surface temperatures due to the presence of gas in the coolant are of interest with resoect to the integrity of rods. To evaluate the margins of safety of a subassembly, the following information must be available: 
- Distribution of gas entrained by the coolant in a rod bundle.

This means that the averaged gas fraction in a subchannel must be known to calculate the coolant and hence the wall temperature increases due to the presence of gas.

- Dimensions and numbers of individual gas hubbles (bubble spectrum) to calculate the influence of the gas on the temperature variation of the thermal highly loaded rods. The local contact time of a gas bubble at the rod surface is the parameter of main interest.

A purely theoretical solution of these problems is not onssible. The distribution of the gas entrained by the coolant in the very complex flow geometry of a rod bundle must be determined by experiments. The influence exerted by the aas in the coolant on the temperature variation of the rods may be described theoretically by a simple model. However, this model should be varified by experiments. To treat these problems, experimental and theoretical investigations have been carried out in three steps:

- Determination of the distribution of the averaged gas fraction within a liquid flowing axially through a rod bundle and of the bubble spectrum (water/air experiments).

- Development of a calculation model to describe the transient temperature field within a rod under the conditions of liquid/gas flow.

- Measurement of the temperature response in a heated fuel rod simulator for known gas fractions in a liquid to support the computational model developed (sodium/argon experiments). 
2. EXPERIMENTAL DETERMINATION OF THE DISTRIBUTION OF THE AVERAGED GAS FRACTION IN THE SUBCHANNELS

From heat transfer point of view, the critical locations in the heated subassembly develop where local gas concentrations become high. Since the outlet of a rod bundle experiences the larqest volume of transported gas the distribution of gas should be determined across the outlet cross section of the bundle and should be related to the gas distribution at the inlet of the subassembly. Therefore the present experiments are carried out under the following orerequisites:

- The measurement should be carried out at the outlet cross section of the bundle.

- The outlet geometry of the bundle should allow the measurement of representative gas distributions comparable with measurements inside the subchannels.

- Two different types of inlet gas distribution profiles, namely uniform and non-uniform, should be maintained so that the influence of the rod bundle on the gas distribution can be well interpreted.

The experiments were carried out in water using air as gas. It will be shown in section 3.1 that this procedure facilitated the experiments without influencing the transferability of the experimental results to sodium/argon conditions. The water loon and the air supply system were designed for the following maximum operation conditions:

\begin{tabular}{|c|c|c|}
\hline Water: & Pump mass flow rate & $11 \mathrm{~kg} / \mathrm{s}$ \\
\hline & Pump differential pressure & 4 bar \\
\hline & Temperature & $70^{\circ} \mathrm{C}$ \\
\hline Air: & Air system pressure & 12 bar \\
\hline & Temperature & $20{ }^{\circ} \mathrm{C}$ \\
\hline
\end{tabular}




\subsection{Test Section}

The test section (Fig. 1) consisted of a rod bundle installed vertically between a mixing chamber at the bottom and an outlet chamber at the top. Water entered the mixing chamber where it was continuously mixed with air. The water/air flow passed the bundle and the outlet chamber into a gas separator tank placed at the top of the tast section. Water from this tank was recirculated to the inlet of the test section through a centrifugal pump.

The main characteristics of the test section were:

Rod number

Rod arrangement

Spacers

Rod diameter (D)

Rod pitch $(P)$

$P / D$ ratio

Walt distance (W)

W/D ratio

Rod length

Helical wire lead $(H)$

$H / D$ ratio

Distance between bundle and

measuring plane I
61

hexagonal

wires

$6.0 \mathrm{~mm}$

$7.9 \mathrm{~mm}$

1.32

$7.9 \mathrm{~mm}$

1.32

$1500 \mathrm{~mm}$

$300 \mathrm{~mm}$

50

$1 \mathrm{~mm}$

More details of the test section with inlet and outlet parts are reproduced in the $\mathrm{Fig}$. 1. The lower nart shows the inlet gas distribution measuring plane and two axial positions of the air supply system, namely at $X$ and $Y$. The air supply positions were chosen in such a way that the position $X$ and $Y$ should yield to the formation of representatively uniform $(Y)$ and non-uniform (X) gas distributions at the inlet measuring plane /3/. In addition the air supply nozzle at $X$ and $Y$ could be radially moved from wall to wall so that air could be introduced into the water flow through different radial positions of the nozzle, namely at $X_{1}, X_{2}, X_{3}$, and at $Y_{1}, Y_{2}, Y_{3}$, representing $1 / 4,1 / 2$, and $3 / 4$ of the tube diameters at the position $X$ and $Y$. 
The upper part of the test section consisted of the outlet gas distribution measuring plane and the outlet chamber. The outlet measuring plane was selected $1 \mathrm{~mm}$ downstream of the rod tips as shown in Fig. 2c. The geometry of the rod tip was cylindrical. This was realized on the bas is of earlier experiments to get representative results comparable with measurements within the bundle $14,5 /$. The gas measuring probes were attached to a turnable supporting system in such a manner that the probe mav be tilted as well as moved radially across the bundie. Such a locating arrangement allows to cover the entire cross section of each measuring $p l a n e$. The main measuring traverses $A, B$ and $C$ were used shown in Figures 1 and $2 a$. In addition to these main traverses right and left oriented traverses are shown.

These 9 traverses allowed to realize 3 traverses each in the central subchannels around the center rod of the bundle. This section of the bundle is shown in Fig. $2 b$, where the subchannel numbering is also indicated.

\subsection{Measuring Technique}

The main measuring data were the local gas fractions of the fluid for different flow rates of water and air. Knowing the local gas fraction in numerous points of the flow area the distribution of the averaged gas fractions across the bundle outlet and inlet can be calculated. The main measurement positions are indicated in Fig. 1 .

For gas detection needle-like high frequency (HF) probes are used. The measuring method of $H F$ probes is described in reference $/ 6 /$. Its functional principle is based on measuring the probe voltage which varies with the dielectric properties of gas and liquid at the tip of the probe. In that way it is possible to record the contact time of a bubble at the probe which is proportional to the bubble length. The main dimensions of the probe are shown in Fig. $2 d$. The tip of the probe has an outer diameter of only $0.4 \mathrm{~mm}$ and the resulting influence exerted on the flow field can be considered minor. The data acquisition system is schematically shown in Fig. 3 together with typical measuring signals (Fig. 3b) and their processing. To determine the local gas fraction, the measuring 
signals have been transformed into normalized rectangular signals via a trigger. The flanks of the rectangular signals control an electronic counter which counts the pulses coming from a pulse generator. Then the local gas fraction $\langle\varepsilon\rangle$ is the ratio of the pulses recorded by the counter $(\Sigma N)$ to the total pulses generated during the period of measurements $\left(\tau_{M} F\right)$ :

$$
\varepsilon=\frac{\sum N}{\tau_{M} \cdot F} \cdot 100|\%|
$$

The cross sectional average gas fraction $\bar{\varepsilon}(r)$ can than be obtained by integration of the local gas fraction measured across the section:

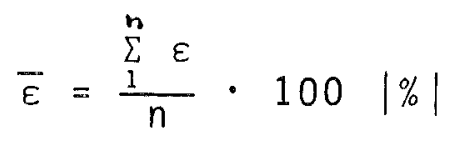

where $n$ is the number of local measuring points across a measuring traverse.

A simple way of calculating the average cross sectional gas fraction may be obtained for a slip ratio $s=1$ from known values of individual flow rates:

$$
\dot{\varepsilon}=\frac{\dot{V}_{A}}{V_{A}+V_{W}} \cdot 100|\%|
$$

where $\dot{V}_{A}$ and $\dot{V}_{W}$ are the volume flow per unit time of air and water phase respectively across the flow section.

Data were obtained at successive distances from the tube wall or the rod wall. In the case of inlet gas distribution measurement, the distance between two successive probe positions was $2 \mathrm{~mm}$ and that at the end of the bundle was $0.5 \mathrm{~mm}$. The measuring time $\tau M$ was taken to be $100 \mathrm{sec}$. This time was large enough to register representative statistical liquid/gas flow characteristics. The definition (3) was used for a global check of the experimental results. 


\subsection{Experimental Parameters}

The measurements were performed in water/air flowing vertically upward through the rod bundle. The whole experiment was carried out in two steps:

Step 1: Realisation of inlet uniform gas distribution profiles and then subsequent measurements of local gas fractions across the outlet subchannels.

Step II: Realization of inlet non-uniform gas distribution profiles and then subsequent measurements of local gas fractions, across the outlet subchannels.

According to this procedure the experimental parameters had the following values:

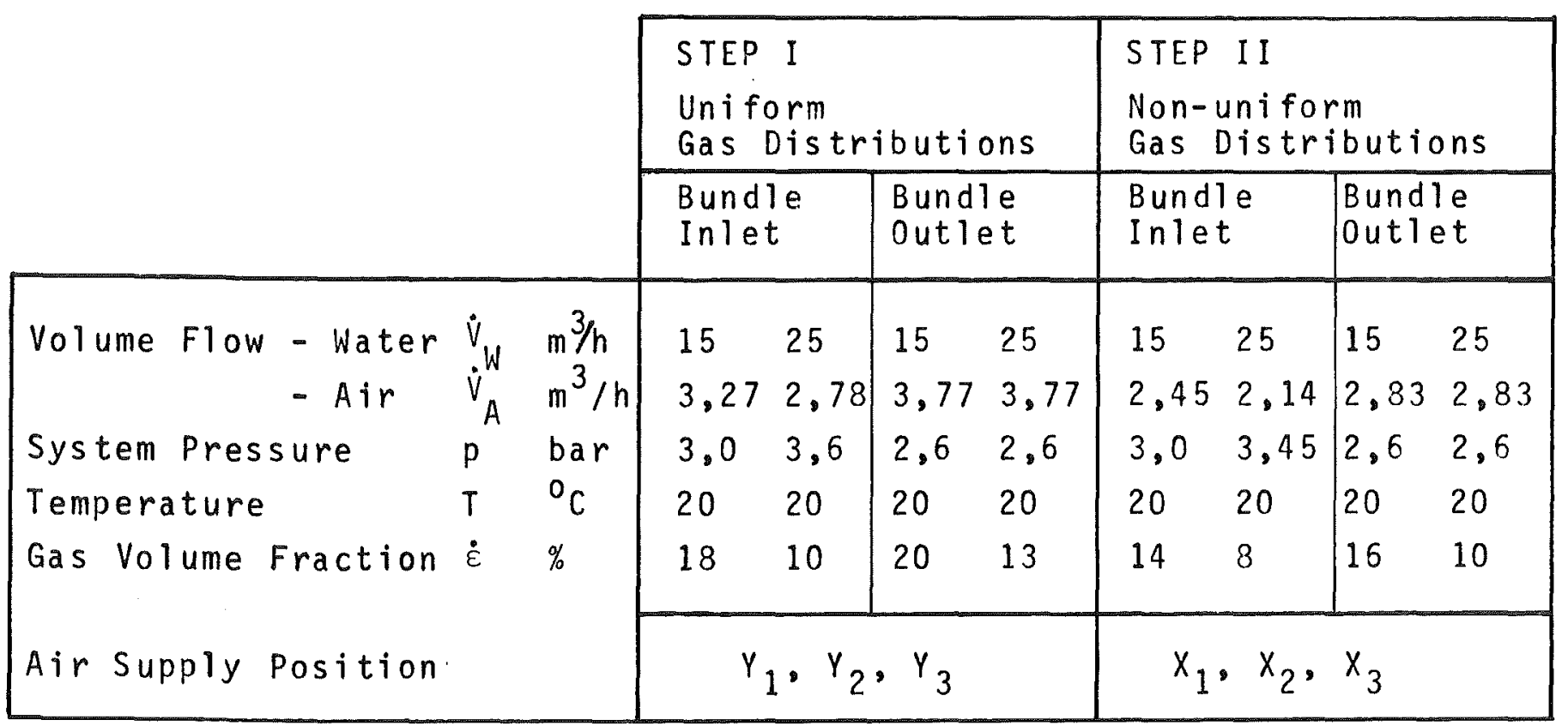

The variation of flow rate parameters was aimed for observation of its influence on local or averaged gas distributions at either inlet or outlet of the rod bundle. The change of air supply positions was exclusively aimed for realisation of either a uniform or non-uniform gas distribution at inlet to the rod bundle. 


\subsection{RESULTS}

Inlet and outlet gas distribution

The gas distribution data will be mainly represented in graphical forms with local gas fractions (\%) in the ordinate and the corresponding radial distances (mm) from the characteristic wall (intat tube; shroud; rod) in the abscissa. Representative results will be discussed below.

The measured uniform and non-uniform inlet gas distributions are shown in Fig. 4 and Fig. 5 respectively. From Fig. 4 it can be seen that the measured inlet gas distribution for gas supply in $Y$ for the two flow rates of water/air ( $\dot{\varepsilon}=18$ and $10 \%$ ) shows a clearly uniform distribution. The air supply positions $\left(Y_{1}, Y_{2}\right.$, $V_{3}$ ) have no influence on the gas distribution. This is demonstrated by measurements across the main three traverses $A_{Z}, B_{Z}, C_{Z}$. Also the change of flow rate has practically no influence on the pattern of gas distribution. The increase of gas fractions near the wall is most likely due to the formation of vortices in this region $/ 7 /$.

The measured inlet gas distribution for gas supply in $x$, represented in Fig. 5, for the two flow rates of water/air ( $\dot{\varepsilon}=14$ and $8 \%$ ) shows a clearly non-uniform and extremely localized gas distribution pattern in contrary to the results mentioned above. The air supply positions $\left(x_{1}, x_{2}, x_{3}\right)$ as well as the flow rate are of influence, measured by different orientations of the probe traverse $A$ ( $A_{r}$, $\left.A_{z}, A_{1}\right)$. The air supply positions at $x_{1}$ and $x_{3}$ near the tube walls give comparable gas distributions also near the tube walls. The air supply position $x_{2}$ in the center results in a center oriented gas distribution, clearly shown on the right side of Fig. 5 where lines of same gas fraction are plotted. The water flow rates show only a small influence on the measured gas distribution.

The measured outlet gas distributions for uniform gas inlet and for the two flow rates of water/air are plotted in Fig. 6. The 
cross-sectional distributions of all the traverses show similar pattern and they are globally uniform, whereas the gas distributions in individual subchannels are non-uniform. The maximum gas fraction appears in most of the cases near the spacer or between two adjacent subchannels where probably flow separation occurs. An influence of the water flow rate at inlet on the gas distributions at outlet can not be deduced from these measurements.

The measured outlet gas distributions for non-uniform gas inlet condition for the two flow rates of water/air are shown in Figs. 7 and 8 respectively. From both plots it can be seen that the averaged gas distributions are non-uniform too. The radial increase or decrease in gas fractions of individual subchannels can easily be related to the inlet gas distribution but in general the gradual increase or decrease is smaller. There are subchannels containing nearly no gas and others where the gas content is as high as 3 times the average cross-sectional value.

For comparison measured gas distributions have been plotted for the subchannels around the central rod of the bundle with uniform $\left(V_{1}\right)$ and non-uniform $\left(X_{2}\right)$ gas distribution at the inlet in Figs. 9 and 10 for two different flow rates of water/air. The data for uniform gas distributions are identical with the results shown in Fig. 6, whereas the data for non-uniform gas distribution were taken in separate measurements. The measurements are shown first for comparable traverses in geometrically similar subchannels with respect to the relative positions of rods and spacers $(1-3-5$, 2-4-6) and then for the three traverses in each of the six subchannels. Gas distributions in the subchannels were measured from three possible directions as shown in Fig. $2 b$ and in the individual plots. From the figures it can be seen clearly that the average gas fractions in these subchannels are directly dependent on the inlet gas distribution: for uniform gas distribution at the inlet it is almost the same as the calculated cross-sectional mean value whereas for centric non-uniform gas distribution profile at the inlet it is 2 to 3 times higher than the calculated cross-sectional mean value. In addition it can be seen:

- The measured local gas fractions in geometrically similar subchannels show a regular course. 
- The amount of gas in the subchannels is different for the different subchannels.

- The gas distributions across three traverses $(A-a, B-b$, $C-c$ ) in each of the geometrically similar subchannels are different.

Due to the helical wire spacers wrapped around each rod of the bundle a swirl flow exists between the outmost row of the rods and the shroud. This was observed.first in single phase flow experiments with individual heated pins of the bundle /2/. A similar flow effect leads to a sinus like gas distribution along the wall subchannels of the bundle (Fig. 11b). As mentioned before, non-uniform gas distributions at the inlet remain also non-uniform at the outlet. But in case of asymmetrically non-uniform gas distributions there exists a positional change of local gas fraction distributions across the bundle from the inlet to the outlet. This may be better observed from Fig. 11 where gas distributions in the wall subchannels around the bundle periphery at the outlet are plotted for uniform (Fig. 11a) and non-uniform (Fig. 11b) gas distribution at the inlet. It can be seen that the case of uniform gas distributions at the inlet the measurements at the outlet show also uniform distributions. But for asymmetrically non-uniform gas distributions at the inlet (e.g. at $x_{1}$ ) the position of maximum gas fraction at the inlet appears at the outlet 180 degree around the periphery. This fact is demonstrated at $X_{3}$ as shown in the same Fig. 11 b.

In both graphs for uniform and non-uniform gas distributions at the bundle inlet the measured values in the wall subchannels at the bundle outlet show a scattering band but the above mentioned swirling effect can clearly be deduced.

\section{Bubble frequencies and contact times}

The registered data were evaluated to get the frequencies and the contact times of the bubbles. In this case the probe was positioned in the center of each individual subchannel. These data were evaluated for uniform and non-uniform gas distribution across the bundle inlet and for the individual subchannel geometries. It could be shown that uniform or non-uniform gas distributions have no 
direct influence in these results and that mainly the average gas fraction in a subchannel is of imoortance.

The results are shown in Fig. 12 where the bubble frequency is plotted against the contact time. Small contact times mean small bubble dimensions. The parameter is the local aas fraction measured in the center of a subchannel. Very high bubble frequencies are registered with very small contact times. During the measuring time of $100 \mathrm{~s}$ roughly $10^{3}$ bubbles where registered showing contact times of 2 - 4 ms. This means that at $3 \mathrm{~m} / \mathrm{s}$ mean flow velocity the bubble lengths are between $6-12 \mathrm{~mm}$. As will be shown later, these bubbles are of no importance for a local surface temperature variation. On the contrary, bubbles were registered having up to 24 - $30 \mathrm{~ms}$ contact times or 72 - $90 \mathrm{~mm}$ lengths and hence reveal a remarkable influence on the local surface temperature variation. Such large bubbles can, however only be registered once per $100 \mathrm{sec}$.

\section{THEORETICAL CONSIDERATIONS}

\subsection{Transferability of Water/Air Results to Sodium/Argon}

To proof the transferability of the water/air results to sodium/ argon the generalized flow pattern map for flow of liquid/gas mixtures (Fig. 13) was used /8/. This map represents the modified superficial liquid velocity $Y u_{S L}$ versus the modified superficial gas velocity $X u_{S G_{x}}$. In that way different flow patterns can be clearly indicated. The superficial liquid or gas velocities can be calculated from the liquid/gas mixture velocity $u_{m}$ in the following way:

$$
\begin{aligned}
& u_{m}=\left(V_{W}+V_{A}\right) / A \\
& u_{S L}=(1-\dot{\varepsilon}) u_{m} \quad(\dot{\varepsilon} \sim \bar{\varepsilon}) \\
& u_{S G}=\dot{\varepsilon} u_{m}
\end{aligned}
$$

The modification is expressed by the transformation factors $Y$ and $X$ which are defined as /8/: 


$$
\begin{aligned}
& Y=\left(\rho_{N a} \cdot \sigma_{W / A} / \rho_{W} \cdot \sigma_{N a / A r}\right)^{1 / 4} \\
& X=\left(\rho_{A r} / \rho_{A}\right)^{1 / 2} \cdot Y
\end{aligned}
$$

These equations result that the viscosities are of no influence and that the densities and surface tensions are of minot influence on the superficial velocities. Both factors $Y, X$ reach for the sodium/argon system values $<1,0$.

The operation range of the experiments in water/air at uniform and non-uniform gas distributions at $15 \mathrm{~m}^{3} / \mathrm{h}$ water flow are shown in Fig. 13 together with the sodium/argon values converted from the water/air measurements. The bandwidths are represented by the measured gas fractions of $\bar{\varepsilon}=20 \%$ (uniform gas distribution) and $\bar{\varepsilon}=$ $40 \%$ (non-uniform gas distribution). It can be seen that the water/ air results are well within the slug flow range. This could also be supported experimentally by measurements of the bubble contact times. For non-uniform gas distribution the measured gas contact times reach up to $30 \mathrm{~ms}$, representing gas bubble lengths of up to $60 \mathrm{~mm}$. As the transformation factors are $<1.0$ the operation ranges move to smaller superficial gas velocities and hence partially into the bubble flow range, e.g. to smaller bubble lengths. The influences of the flow channel diameter (subchannel) in the bubble and slug flow ranges can be neglected / $/ 8$.

\subsection{Calculation Model Describing the Transient Temperature} Variation of a Cylindrical Rod

Two types of effects arise in the verification of theoretical investigations of the transient rod temperature variations in sodium/ argon flow $/ 9 /$.

- Due to the reduced heat capacity of the sodium/argon flow the heat-up rate increases and with it the bundle outlet temperature of the coolant. This effect is influenced mainly by the reduced sodium mass flow rate caused by the gas fraction.

- Fluctuations of the cladding temperatures are superimposed to the above mentioned effect owing to the flow pattern. 
For the case of determining the heat-up rate of the coolant, the one-dimensional problem may be formulated by the energy equation:

$$
\dot{m} \cdot c_{p}\left(\frac{d T_{K}}{d z}\right)=q^{\prime}(z)
$$

where $m$ is the mass flow rate and $q^{\prime}$ the 1 inear rod power and $c_{p}$ the specific heat.

The transient temperature field of a cylindrical rod is described by the Fourier equation of heat conduction:

$$
\nabla(\lambda \nabla T)+q^{\prime \prime \prime}=\rho \cdot c_{p}\left(\frac{\partial}{\partial \tau} \cdot T_{K}\right)
$$

Neglecting the azimuthal temperature variation as well as the axial heat conduction the one-dimensional (radial) differential equation assumes the following form:

$$
\frac{1}{r}\left(r \cdot \lambda \cdot \frac{\partial}{\partial r} \cdot T\right)+q^{\prime \prime \prime}=\rho \cdot c_{p}\left(\frac{\partial}{\partial \tau} \cdot T_{K}\right)
$$

where $q^{\prime \prime \prime}$ is the local volumetric heat generation, $\lambda$ the heat conductivity and $\rho$ the density.

The influence of gas bubbles on the coolant and wall temperature in axial direction is determined using a series of simultaneous onedimensional heat conduction calculations. For this purpose, a Lagrangian coordinate system which moves in the axial direction with the same velocity as the coolant, is preferred.

The superimposed temperature fluctuations are determined by using a one-dimensional model. The boundary conditions at the surface of the rod are given by the heat transfer between the rod and the coolant. It is assumed that the heat transfer is constant when sodium passes the rod surface and the heat transfer is interrupted when a gas bubble arrives at the considered point of the rod; i.e. it is assumed that the phase boundaries of the flow are idealized so that a sequence of sodium slugs and gas slugs is generated. This 
consideration is conservative as no residual sodium film between rod surface and gas bubble is taken into account.

The modified RELAX code /10/ solves the one-dimensional, lumped parameter, transient heat conduction problem by using a finite difference approximation technique with a sufficient number of radial nodes to describe the rod construction. Thus, concentric layers of different materials with temperature dependent properties /13/ can be used to simulate the thermocouple position and the rod construction for the heater rod in the test equinment.

The discretisation of the calculation model is shown in Fig. 14 . The fuel rod is shown with the assumed gas and liquid slugs flowing along the rod. The wall is subdivided in 6 radial nodes one representing the thermocouple position in the experiment used to support the calculation model. The signals of that radial thermocouple position are used to compare experiment and calculation. It must be stated, that due to damping effects of the rod the measured temperature variation is not the highest temperature variation. This occurs at the rod surfaces, and is shown in Fia. 15 where the calculated temperature variations at the rod surface and at $0,25 \mathrm{~mm}$ inward from the canning surface (thermocouple position of the experiment described under 4.) are indicated versus the contact time. The curves apply for the following parameters:

Fluid temperature

Gas fraction

Heat transfer coefficient

Heat power

Four different gas contact times $2 ; 10 ; 30 ; 100 \mathrm{~ms}$
$340{ }^{\circ} \mathrm{C}$

$50 \%$

$11: \sqrt{ } / \mathrm{Kcm}^{2}$

$40 \mathrm{~W} / \mathrm{cm}^{2}$

As can be seen for a given axial rod position:

- The canning temperature increases during the gas bubble contacttime and decreases as soon as sodium reaches the rod surface.

- The amplitude of temperature variation increases with the gas contact time.

- The transient temperature profile in all cases remains similar (influenced only by the geometry, material properties and heat power at the surface). 
- The transient temperature profile is different for the considered radial canning positions. The temperature variation at the canning surface is higher than at the thermocouple $\left(r_{1}\right)$-gosition due to damping effects of the rod.

The calculated values show that only the contact time of the bubbles is decisive for the cladding temperature variation. This means that the ratio of gas bubble length to bubble velocity (contact time) is characteristic of the transient temperature field in the rod. The amplitude of temperature variation is then proportional to the heat flux density and the contact time of a bubble at the wall.

Therefore the differences between the maximum canning temperature and the mean coolant temperature are related to the heat nower $\left(\left(T(r)_{\max }{ }^{-T_{k}}\right) / q^{\prime \prime}\right)$ and plotted versus the contact times of the bubble. The results are shown in Fig. 16 for a gas fraction of $50 \%$ and $25 \%$ for 3 different radial positions within the canning wall. The following conclusions can be drawn:

- The normalized temperature difference increases with increasina contact time.

- With increasing distances from the rod surface to the rod center the temperature differences increases but the temoerature variations become smaller.

- Lower gas fractions result in smaller temoerature increases.

A similar plot is shown in Fig. 17 where the heat transfer coefficient is varied. It can be seen that increasing temperaturedifferences are indicated with decreasing heat transfer coefficients, an expected dependency. 


\section{EXPERIMENTAL INVESTIGATIONS OF TRANSIENT TEMPERATURE VARIATIONS}

In order to support the computational model for the determination of transient temperature fields within a rod under the conditions of liquid/gas floy, experiments have been performed in a sodium/ argon flow /1, $12 /$.

\subsection{Test section}

An annular test section was used as shown in Fiqure 18. The test section consisted of a heatable rod as fuel pin simulator, installed in a circular tube between a mixing and an outlet chamber. Sodium entered the mixing chamber where it was continuously mixed with argon of the same temperature. The main characteristics of the test section were:

Rod diameter

Annulus outer diameter

Ratio of radii

Heated rod length

Max. heating capacity

Max. sodium temperature

Spacers
$9 \mathrm{~mm}$

$16 \mathrm{~mm}$

0,526

$700 \mathrm{~mm}$

$250 \mathrm{l} / \mathrm{cm}$

$550^{\circ} \mathrm{C}$

pins

Accuracy of the measured results requires high thermal load and reliable instrumentation of the rod cladding by thermocouples. The heater rod was selected on the basis of extensive experimental R\&D work performed at KfK Karlsruhe / 13/. It consisted of a tubular electrical heater element, a surrounding boron nitride (BN) insulation layer and a cladding tube.

\subsection{Measuring technique}

Two measuring planes were installed at 100 and $200 \mathrm{~mm}$ distance from the end of the heated rod. Measuring plane I is sketched in the Fig. 18. Four measuring places were installed equally spaced from each other at the circumference of the test arrangement. Two of those were equipped each with two non-insulated thermocouples of $0,5 \mathrm{~mm}$ diameter. Their tips reached $2 \mathrm{~mm}$ into the annulus 
and they were inserted with $2 \mathrm{~mm}$ axial distance. This pair of thermocouples was used as chen detector to indicate gas bubbles or to measure the fluid temperatures. In addition two measuring places were equipped each with three non-insulated thermocouples allowing the simultaneous registration of gas bubbles and fluid temeratures. To record the wall temperatures at each measuring 3 lace a $0,45 \mathrm{~mm}$ dia BN-insulated thermocouple was embedded $0.25 \mathrm{~mm}$ below the surface of the heater rod. Measuring plane II was instrumented similarly as measuring plane I but only equipped with two measuring locations. It was used to demonstrate the extend of a bubble in axial and azimuthal direction in the annulus, for verification of slug flow and to register the flow velocities by transit time measurements. The signal correlations of both measuring planes were excellent.

The sensors were installed at axial and azimuthal positions in such a manner that correlations were possible between measured temperature variations in the coolant, measured contact times of the bubble, and measured temperature variations in the claddina. Sodium outlet and inlet temperatures were measured before and after the heated part of the rod as well as the rod power and the argon and sodium mass flow rates to allow proper heat balances. The argon temperature was measured before the mixing chamber. The tests were performed for the following operating conditions:

Heat flux density

Sodium flow

Gas fraction

Sodium temperature at measuring planes

$$
\begin{aligned}
& 20 ; 40 ; 80 \mathrm{y} / \mathrm{cm}^{2} \\
& 0,13 ; 0,26 \mathrm{~kg} / \mathrm{s} \\
& 25 ; 50 \% \\
& 350-400{ }^{\circ} \mathrm{C}
\end{aligned}
$$

The chosen sodium flow represents fluid velocities in the annulus of 1 and $2 \mathrm{~m} / \mathrm{s}$. This flow rate guaranteed slug flow, as demonstrated in a series of earlier experiments. The chen detectors record the gas bubble contact times. Similarly as shown in Fig. 3, the sum of all contact times of the gas phase divided by the total measuring time gives the gas fraction at the measuring place. 


\subsection{Results}

Typical measuring signals are shown in Fig. 19 where the measured bubble contact time, the time dependent wall and coolant temperature variations for a representative measuring oosition are registered for the following operating conditions:

$\begin{array}{ll}\text { Argon fraction } & 50 \% \\ \text { Heat flux } & 40 \mathrm{~W} / \mathrm{cm}^{2} \\ \text { Sodium flow rate } & 0,13 \mathrm{~kg} / \mathrm{s}\end{array}$

The graph shows that as soon as the bubble reaches the chen detectors the wall temperature increases rapidly up to a maximum value which is reached at a time where the bubble is followed by a sodium slug. This reduces the wall temperature instantaneously and leads to an increase of the coolant temperature resulting from the stored heat within the heater rod which is transferred to sodium at this moment. A typical temperature variation within the heater rod cladding is also shown. It is calculated for a layer depth of the cladding which represents the measuring point of the embedded thermocouples and for the operational conditions (heat flux, bubble length, coolant temperature) prevailing in the experimental test. The heat transfer coefficient was assumed to be $7 \mathrm{~W} / \mathrm{cm}^{2} \mathrm{~K}$. These results show good agreement between calculation and measurement. Also the measured values show that only the contact time of the bubbles is decisive for the cladding temperature variation.

The bubble spectrum was subdivided into discrete intervals characterized by the intervals of contact time in steps of 2.5 ms. This procedure resulted in 20 different bubble lengths for a gas fraction of $25 \%$ and in 40 different bubble lengths for a gas fraction of $50 \%$ in the liquid flow. The evaluation of the experimental data was carried out in analogy to the calculations. That means that the difference between maximum measured cladding temperature and mean measured fluid temperature was used and related to the rod power of the experiment. These normalized temperature differences were plotted versus the gas contact times of the experiment. All results for the same temperature difference and bubble length were averaged arithmetically and the standard deviation was determined. 
In Fig. 20 the normalized temperature differences resulting from the experiments are plotted as a function of the gas bubble contect time, with the gas fraction varied as the parameter. At the ordinate the measured averaged value for the case of single phase sodium flow is also indicated. For the nominal thermocouple position in the wall the normalized temperature differences were also calculated as function of the contact times and for the same operational conditions, namely of a gas fraction of 50 or $25 \%$, respectively. In these calculations the simplified model assuming constant fluid temperature was used. During single phase sodium flow a heat transfer coefficient of $7 \mathrm{~W} / \mathrm{cm}^{2} \mathrm{~K}$ was assumed and in the presence of a bubble this value was assumed to be zero.

The results show:

- A good agreement between experimentally determined and calculated results.

- The normalized temperature differences increase with increasing contact times of a bubble and with increasing gas fraction in the fluid. The standard deviation evaluated from the scattering of the experimental results for both gas fractions is rough $1 y 10 \%$.

This standard deviation entails beside the variation of the normalized temperature differences the following uncertainties:

- Uncertainties of temperature difference measurements.

- Uncertainties of the radial position of the thermocouple in the cladding wall.

- Uncertainties in determining the gas fraction and the power density at the measuring position.

The standard deviation mainly depends on the irregular follow-on of bubbles of different lengths. Although this is of no remarkable influence for the practical design procedures, however, it must be kept in mind.

Summarizing the results it can be stated that despite of the simplifications made in the assumed theoratical model, the results of the measurements agree well with those of the calculations and justify the simplifications assumed. It must be noted that when a residual sodium 
film of, for instance, $0.1 \mathrm{~mm}$ between the rod surface and the gas bubble is taken into account the temperature fluctuations resulting from the calculations are reduced by about $10 \% / 14 /$.

\section{SUMMARY AND CONCLUSIONS}

Experiments have been carried out to investigate the influence of gas transported in the coolant of an LMFBR on the temperature variation of highly loaded rods. The following three aspects were considered:

1. The influence of a bundle of hexagonally arranged rods $(P / D=1.3)$ equipped with helical spacers (wires, $H / D=50$ ) on uniform and non-uniform gas distributions in a fluid entering the bundle was investigated by measuring the gas fraction at the bundle outlet section across various subchannel traverses and relating the results to the inlet conditions. Water/air flow was used instead of sodium/argon, and it was shown that this is without influence on the results as the fluid properties are no decisive magnitudes. As slug flow is the interesting flow characteristic for the temperature variation of the rod surfaces the experiments are mainly carried out for this flow situation. The results of gas fraction measurements across the bundle outlet flow area show:

- Uniform gas distribution in front of the bundle fairly remains uniform at the end of the bundle.

- Non-uniform gas distribution entering the bundle results in non-uniform gas distribution leaving the bundle. There exists a smal1 uniformizing effect of the bundle on the gas distribution which shows that the degree of non-uniformity decreases. - In the peripheral subchannels a swirl gas transport along the circumference of the hexagonal shroud is registered clearly. As the local temperature variations of a rod depend on distribution, number and dimensions of the bubbles these magnitudes were determined for subchannels with different gas fractions. The main interest has concentrated on the determination of the contact time of the bubbles. Independent of uniform or non-uniform gas distribution entering the bundle the following statements can be made: 


\section{- For all investigated gas fractions there is a clear dependency} between bubble frequency and contact time. For the same contact time the bubble frequency increases with increasing gas fraction. - Bubbles were registered showing contact times up to $30 \mathrm{~ms}$.

The transferability of the water/air results to sodium/argon was investigated and it could be shown that the transformation factors are near-by unity. Therefore the results of water/air experiments are applicable to sodium/argon flows.

2. A calculation model was evaluated to comoute the influence of bubbles in a sodium flow on the temperature variation of a heated rod. This model is based on simplified thermodynamic assumptions and slug flow. It was supported by experiments in a sodium/argon flow. Experiments were carried out in an annular geometry with heated rod. The instrumented measuring planes were equipped with chen-detectors and thermocouples to register the ras contact times, coolant and wall temperatures simultaneously.

It could be shown for slug flow conditions that the measured wall temperature variations can be well interoreted as functions of bubble contact time, rod power and gas fraction of the flow. The normalized Jlots of the temperature variations show:

- The temperature variations increase with increasing bubble contact times and with increasing ras fraction of the flow.

- The measured temperature variations can well be precalculated assuming proper heat transfer correlation of the single phase sodium flow.

3. The available results allow to calculate the mean coolant temperature rises due to the presence of gas in a sodium flow for a given aas distribution in a rod bundle. For practical reasons this gas distribution can be assumed identical to that prevailing at the bundle entrance as shown by the water/air measurements. This is a conservative consideration. The bundle entrance gas distribution however must be determined exnerimentally for the individual geometrical and hence flo: conditions upstream of the bund $1 e$.

The temperature fluctuations superimoosed to the mean coolant temperature rise due to the presence of gas can be determined 
using the experimentally varified calculation model. The water/ air results however show that this fluctuation is only of importance when the averaged subchannel gas content is high. only in this case bubble contact times and bubble frequencies orevail which remarkably influence the imoact of gas in a sodium flow on the temperature variation of an LMFBR rod bundle. 


\section{REFERENCES}

/1/ H. Hoffmann, K. Marten, E. Baumgärtner, K. Rust:

"The Influence of Gas in a Sodium Flow on the Temperature Variations of High Loaded Fuel Rods"

Fast Reactor Safety Technology. Proc. of the Internat. Meeting. Seatt1e, Wash., August, 1979. La Grange Park, I11.:

American Nuclear Soc. 1979. Vol.5, pp.2523-32

/2/ H. Hoffmann:

"Experimentelle Untersuchungen zur Kühlmittelquervermischung und zum Druckabfall in Stabbündeln mit wende1förmigen Abstandshaltern"; KfK 1843 (1973). BNWL-TR-117 (in English) (1974).

/3/ M. Khan:

private communication (1978)

/4/ M. Chung:

"Experimental Investigations on Air-Distribution in a Water Flowing Through a 61-Rod Bundle With Helical Spacers Journal of Korean Nucl. Soc. 10, Nr. 2, pp.79-86, June 1978

/5/ M. Chung, M. Khan, K. Marten:

private communication (1976)

/6/ St. Muiller:

"Verfahren und Einrichtung zum Identifizieren einer Zweiphasenströmung" in Proc. Reaktortagung Hannover, 4-7 April 1978. Deutsches Atomforum, pp. 170-173 (1973).

/7/ Zia Rouhani:

"Effect of Wall Friction and Vortex Generation on the Radial Distribution of Different Phases"; Journal of Multiphase Flow, Vol. 3, pp. 35-50; (1976). 
18/ G.W. Govier, K. Aziz:

"The Flow of Complex Mixtures in Pipes"

van Nostrand Reinhold Company, NY (1972)

19/ S. Malang, K. Rust:

"Verfahren zur Berechnung des Einflusses von Gasblasen bei Flussigmetallkihlung", Atomwirtschaft-Atomtechnik 21 , p. $579-531$ (1976).

/10/ S. Malang, K. Rust:

"RELAX - Ein FORTRAN-Programm zur numerischen Bestimmung von Temperaturfeldern mittels der Relaxationsmethode der Thermodynamik", Kfk 1053, September 1969.

/11/K. Rust, S. Ma1ang, W. Götzmann:

"PEN - Ein FORTRAN-Programm zúr Bereitstellung physikalischer Eigenschaften von Werkstoffen für Brennstäbe und deren Simulatoren", KfK-Ext. 7/76-1, December 1976.

/12/ K. Marten, E. Baumgärtner

"Experimentelle Bestimmung transienter Temperaturverteilungen an thermisch hochbelasteten Kernbrennstäben unter dem Einfluß einer Argon-Natriumströmung"

Jahrestagung Kerntechnik, DAtF,KTG - Berlin 1980, Tagungsbericht Seite 133 - 36 .

/13/V. Casal:

Development of electrical heaters for fuel pin simulation in LMFBR safety experiments", 8th Meeting Liquid Metal Boiling Working Group, Mol, Belgium 11-13 October 1978.

/14/ A. Islam, K. Rust:

"Der Einfluß von Gasblasen auf die Temperaturverteilung einer thermisch hochbelasteten Oberfläche in einer $\mathrm{Na-Strömung",} \mathrm{in}$ KfK 1274/4, 126.11-12 (May 1975) and KfK 1275/1, 126.12-15 (Ju 7y 1975). 


\section{NOMENCLATURE}

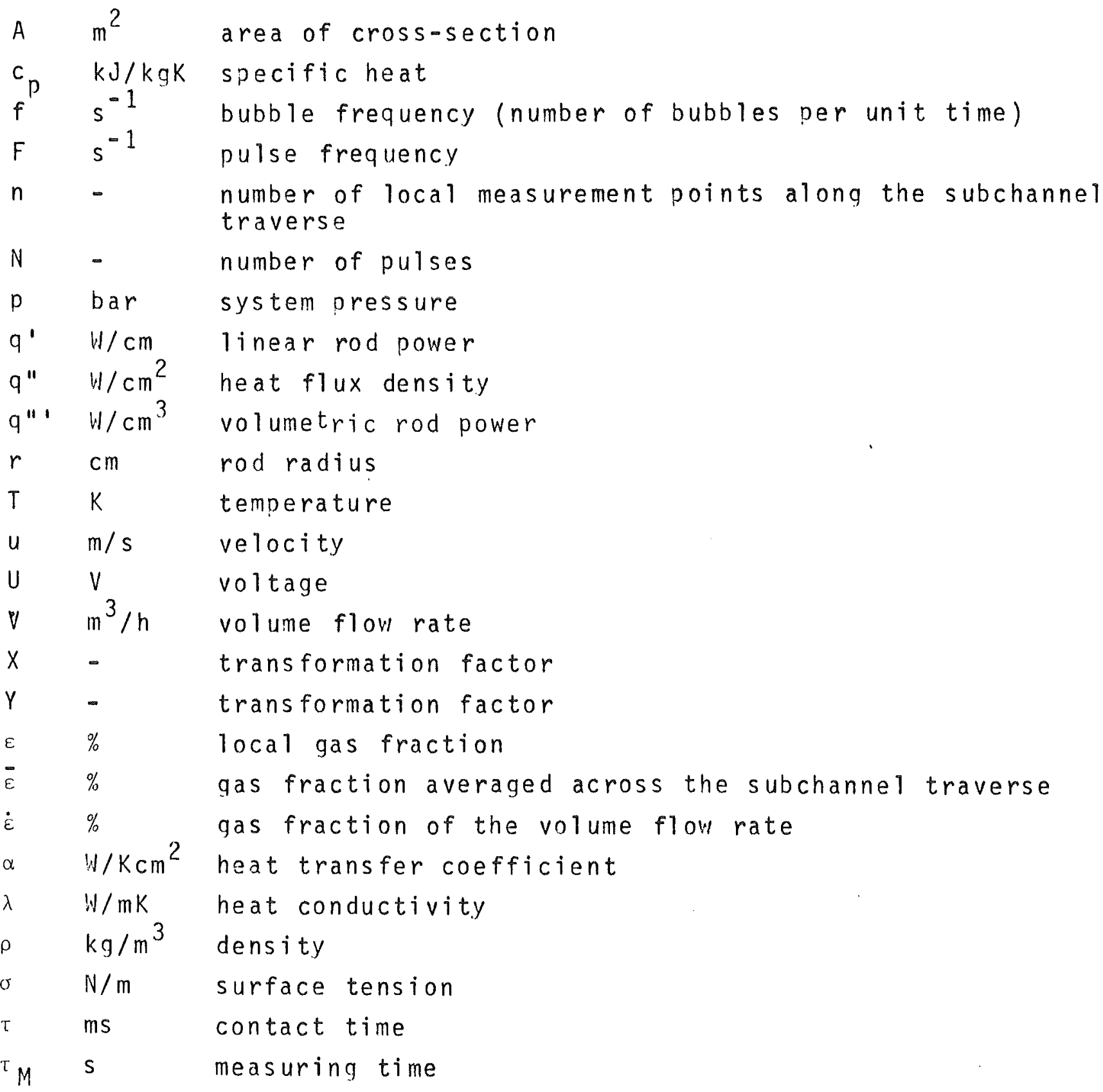

\section{Subscript}

$\begin{array}{llll}\text { A } & \text { air } & \mathrm{Na} & \text { sodium } \\ \text { Ar } & \text { argon } & 0 & \text { surface } \\ \mathrm{C} & \text { canning } & \mathrm{SG} & \text { superficial gas } \\ \mathrm{K} & \text { coolant } & \mathrm{SL} & \text { superficial liquid } \\ \mathrm{m} & \text { liquid/gas mixture } & \mathbb{E} & \text { thermocouple } \\ M & \text { measuring time } & W & \text { Water }\end{array}$




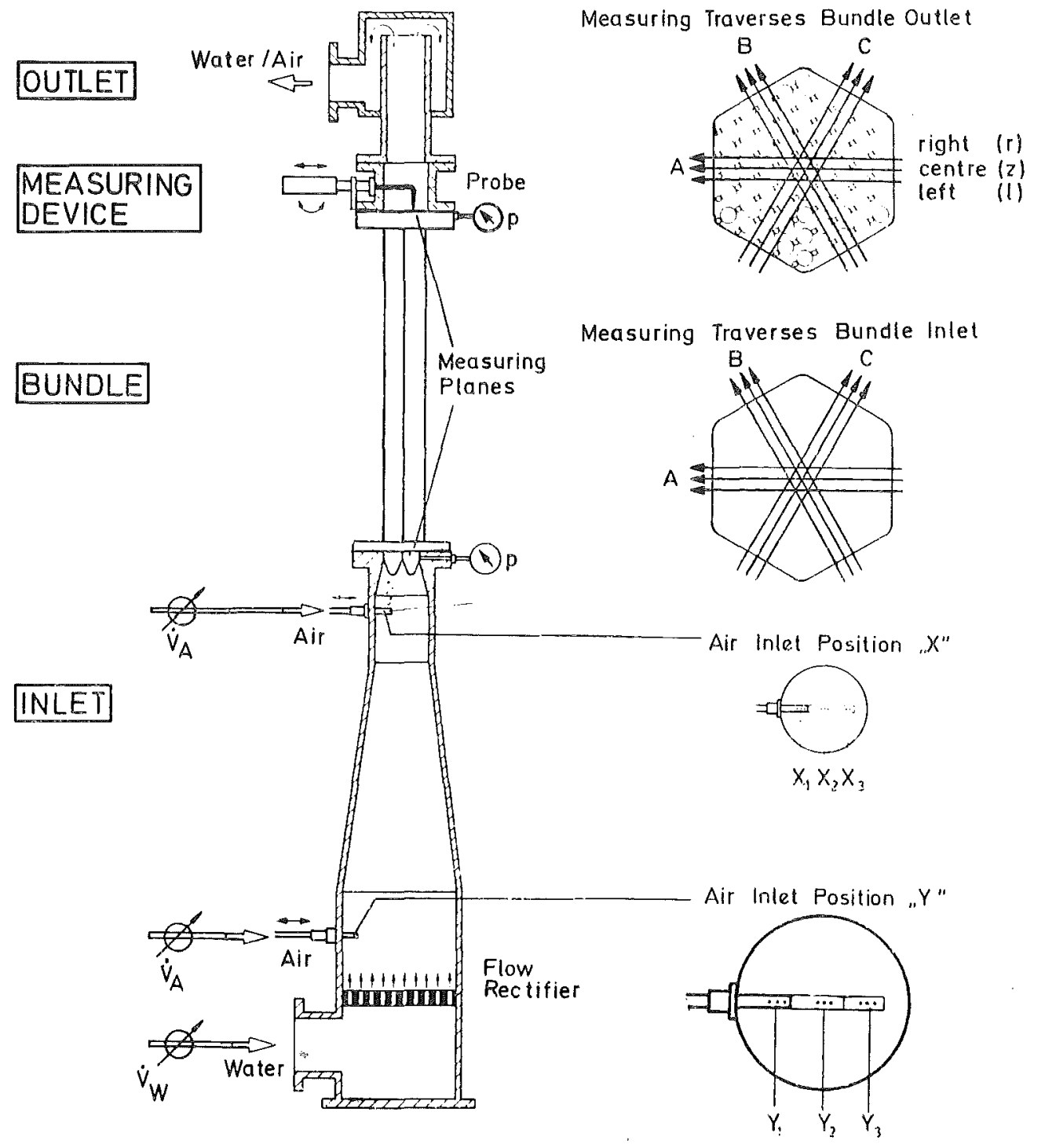

Fig. 1 TEST SECTION 61 ROD BUNDLE 

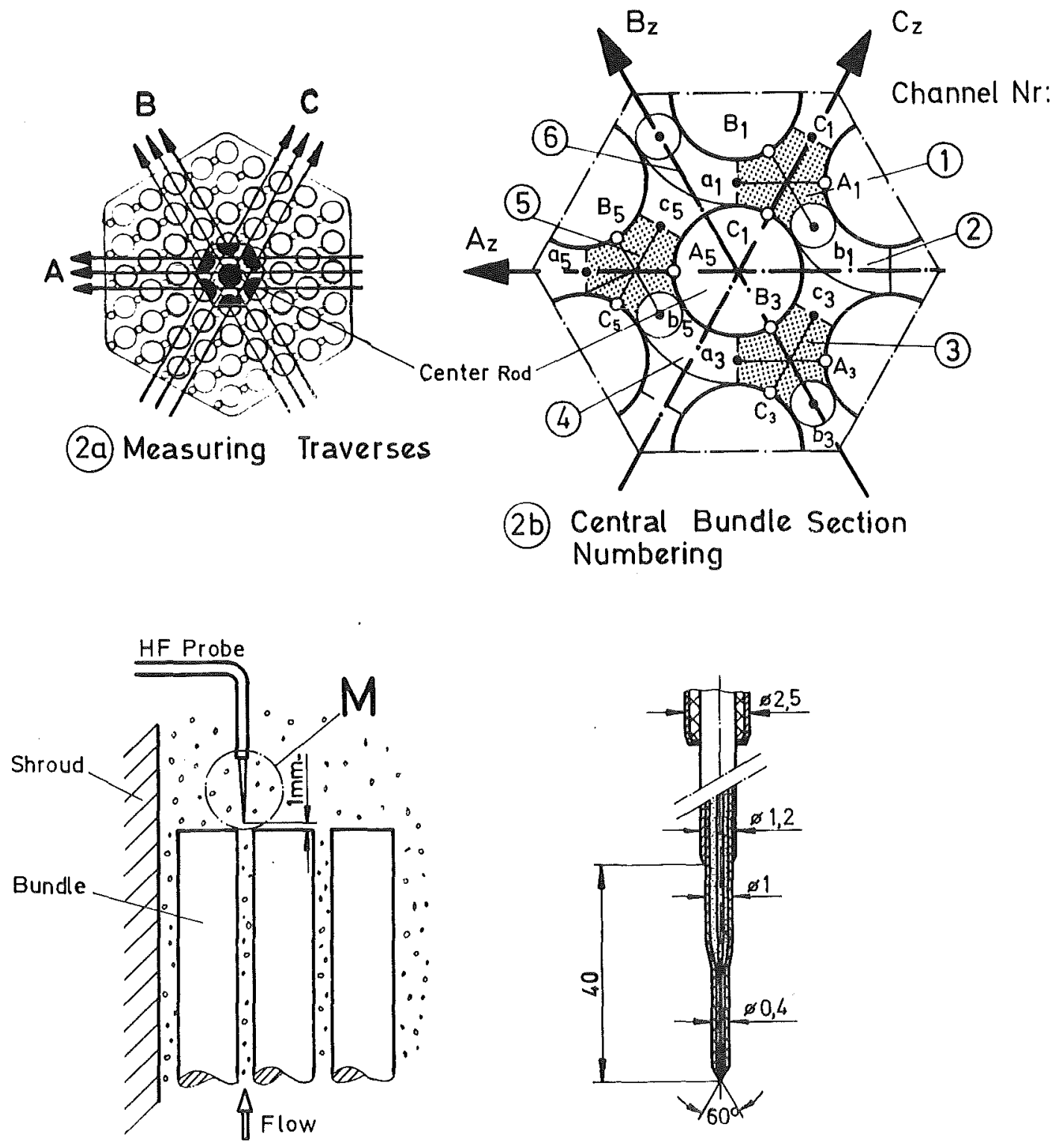

(2c) Longitudinal Section Measuring Probe Position

(2d) Measuring Probe „M"

Fig. 2 DETAILS OF TEST SECTION WITH SUBCHANNEL NUMBERING AND MEASURING PROBE 
HF-Generator

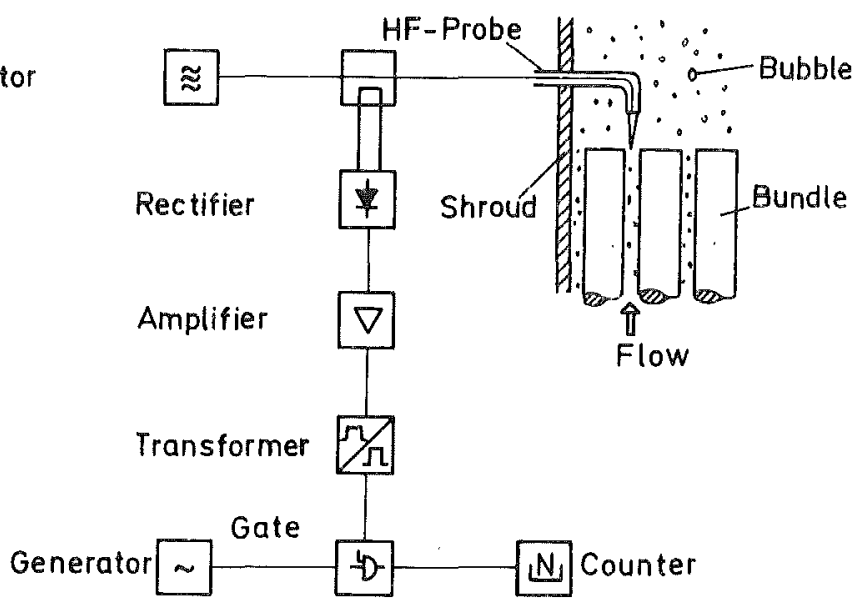

(3a): MEASURING SIGNAL ACQUISITION SYSTEM
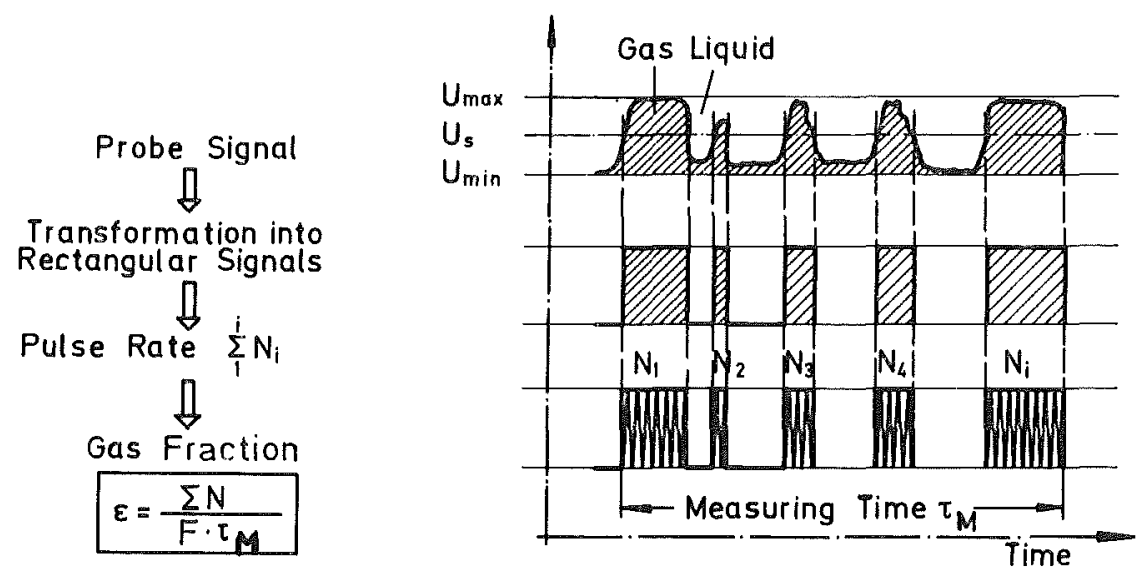

(3D): SIGNAL PROCESSING

Fig. 3 MEASURING PROBE SIGNAL PROCESSING 

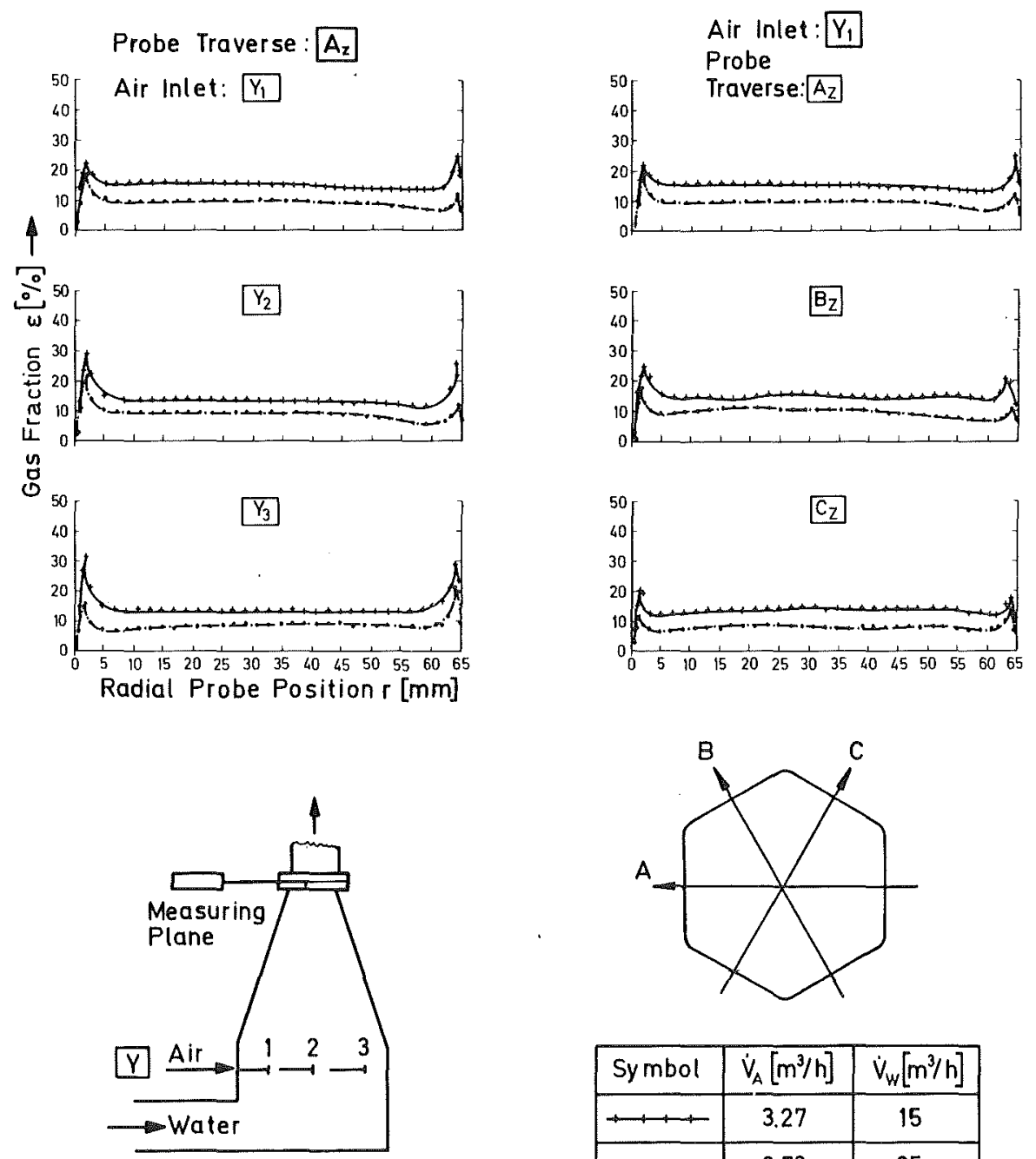

\begin{tabular}{|c|c|c|}
\hline Sy mbol & $\dot{V}_{A}\left[\mathrm{~m}^{3} / \mathrm{h}\right]$ & $\dot{V}_{\mathrm{w}}\left[\mathrm{m}^{3} / \mathrm{h}\right]$ \\
\hline$\longrightarrow$ & 3.27 & 15 \\
\hline$-\cdots$ & 2.78 & 25 \\
\hline
\end{tabular}

Fig. 4 MEASURED GAS DISTRIBUTION AT BUNDLE INLET - UNIFORM GAS DISTRIBUTION 


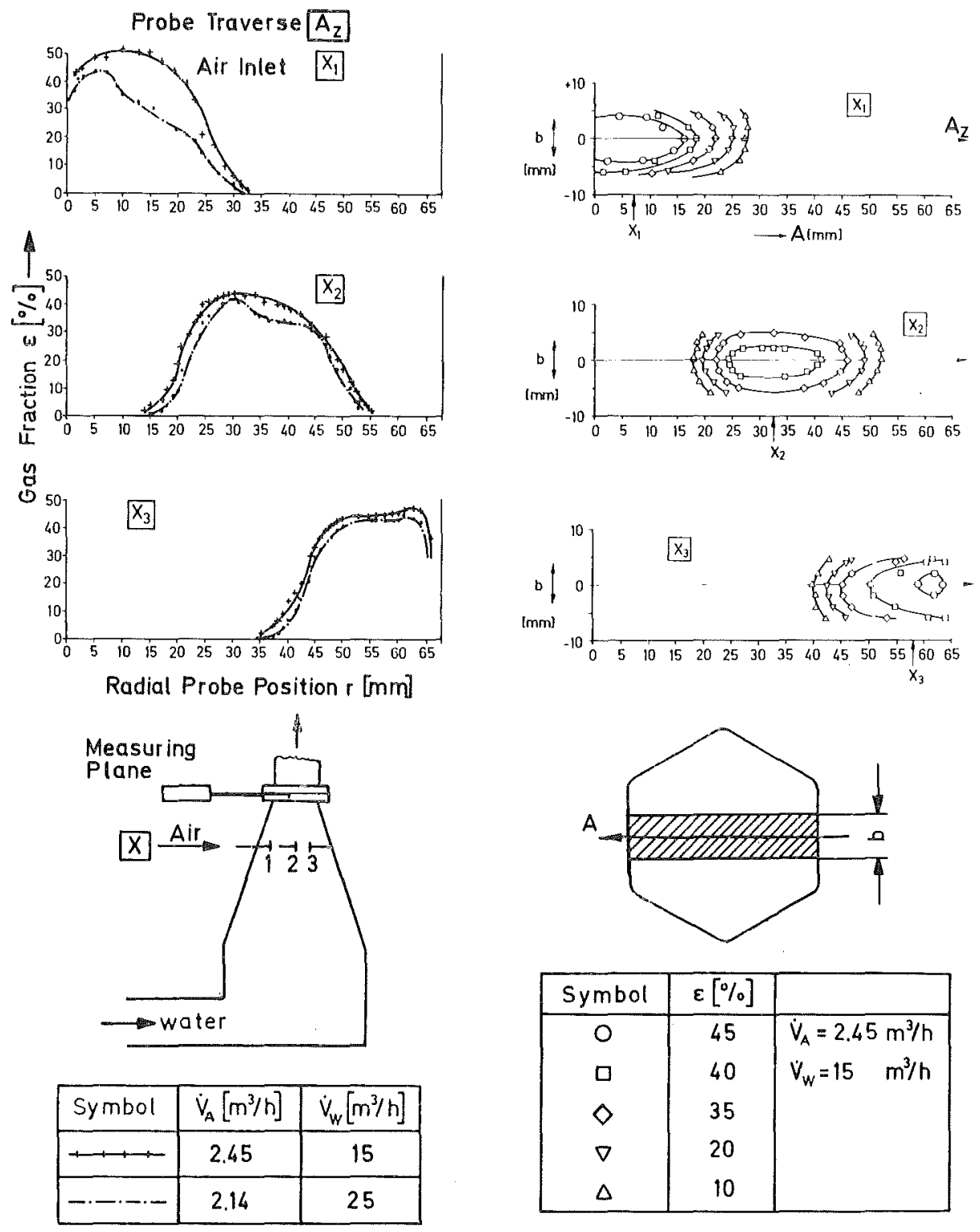

Fig. 5 MEASURED GAS DISTRIBUTION AT BUNDLE INLET - NON-UNIFORM GAS DISTRIBUTION 

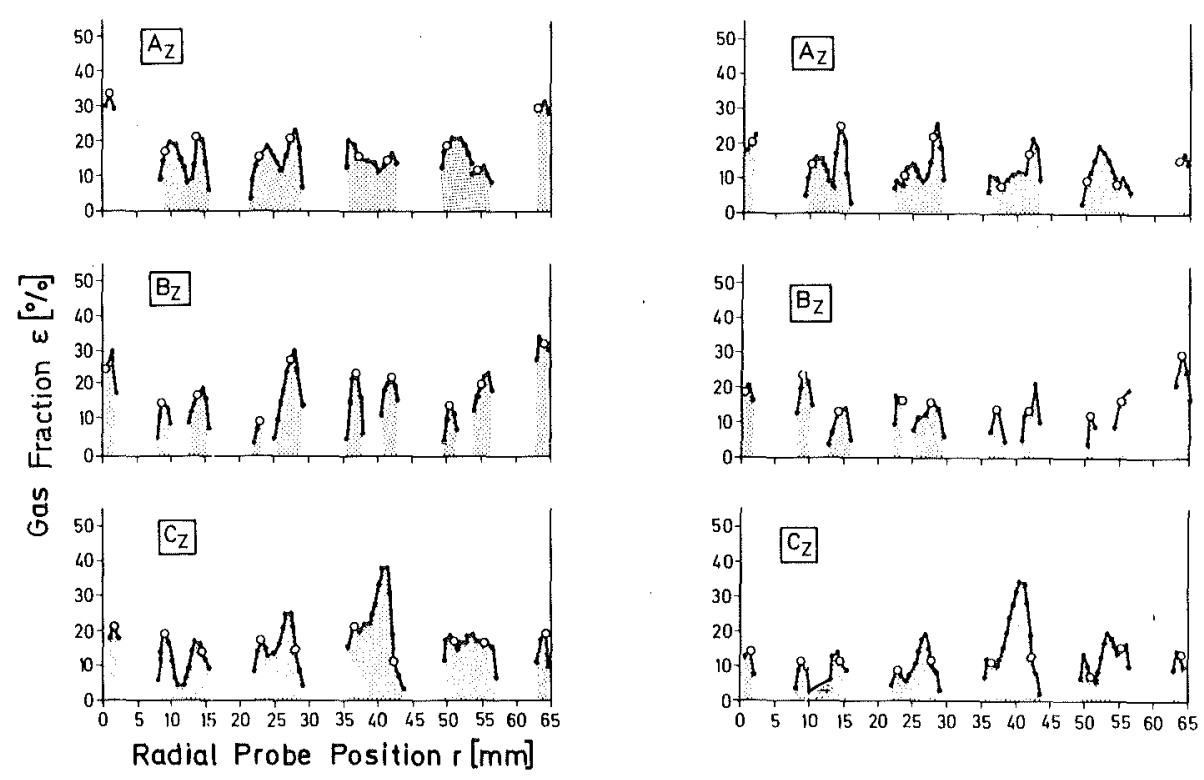

$$
V_{W}=15 \mathrm{~m}^{3} / \mathrm{h}_{;} V_{A}=3.77 \mathrm{~m}^{3} / \mathrm{h}
$$

$V_{W}=25 \mathrm{~m}^{3} / h_{i} V_{A}=3.77 \mathrm{~m}^{3} / \mathrm{h}$
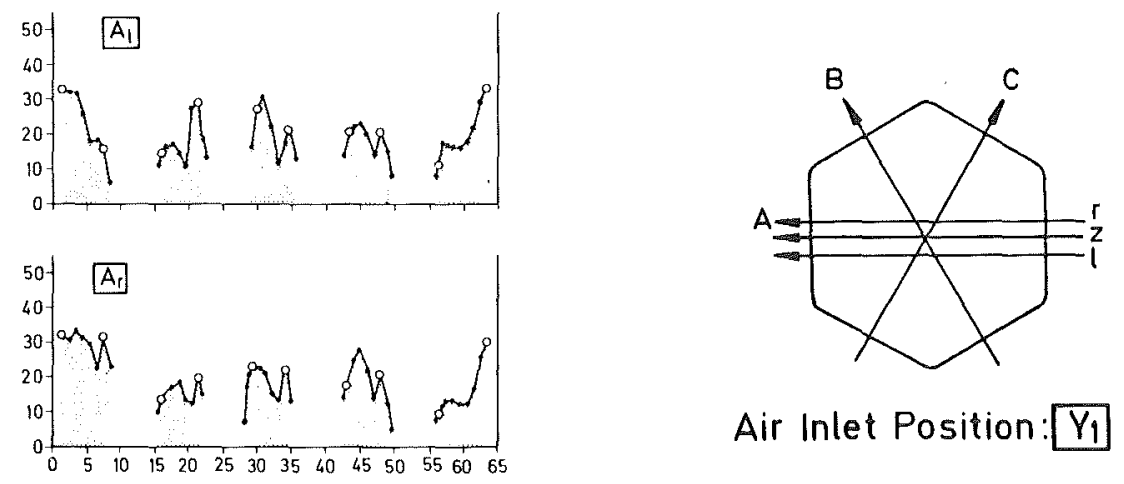

Air Inlet Position: $Y_{1}$

Fig. 6 MEASURED GAS. DISTRIBUTION AT BUNDLE OUTLET - UNIFORM GAS DISTRIBUTION AT BUNDLE INLET 

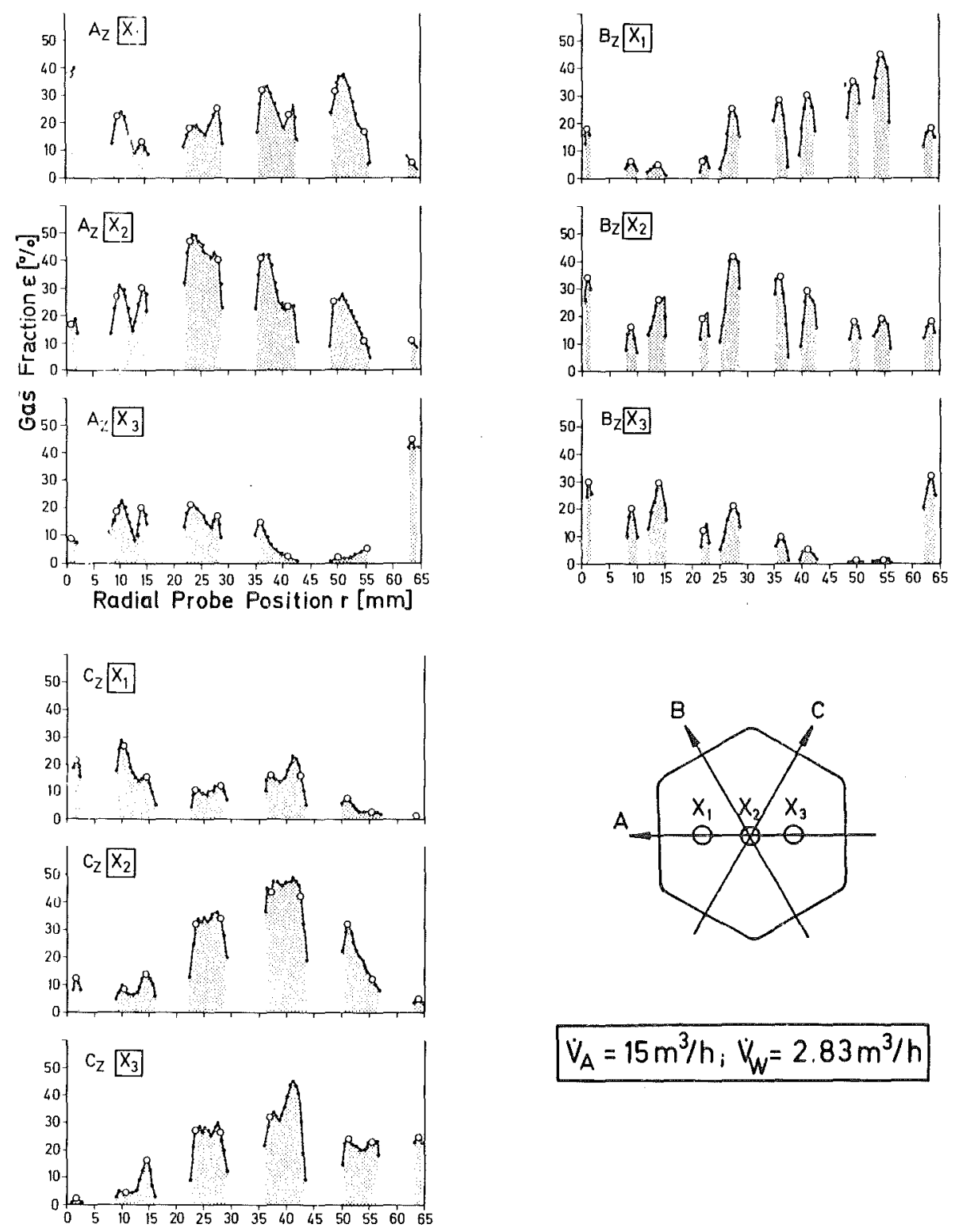

$\dot{V}_{A}=15 \mathrm{~m}^{3} / h_{;} \dot{V}_{W}=2.83 \mathrm{~m}^{3} / \mathrm{h}$

Fig. 7 MEASURED GAS DISTRIBUTION AT BUNDLE OUTLET - NON-UNIFORM gAS DISTRIBUTION AT BUNDLE INLET 

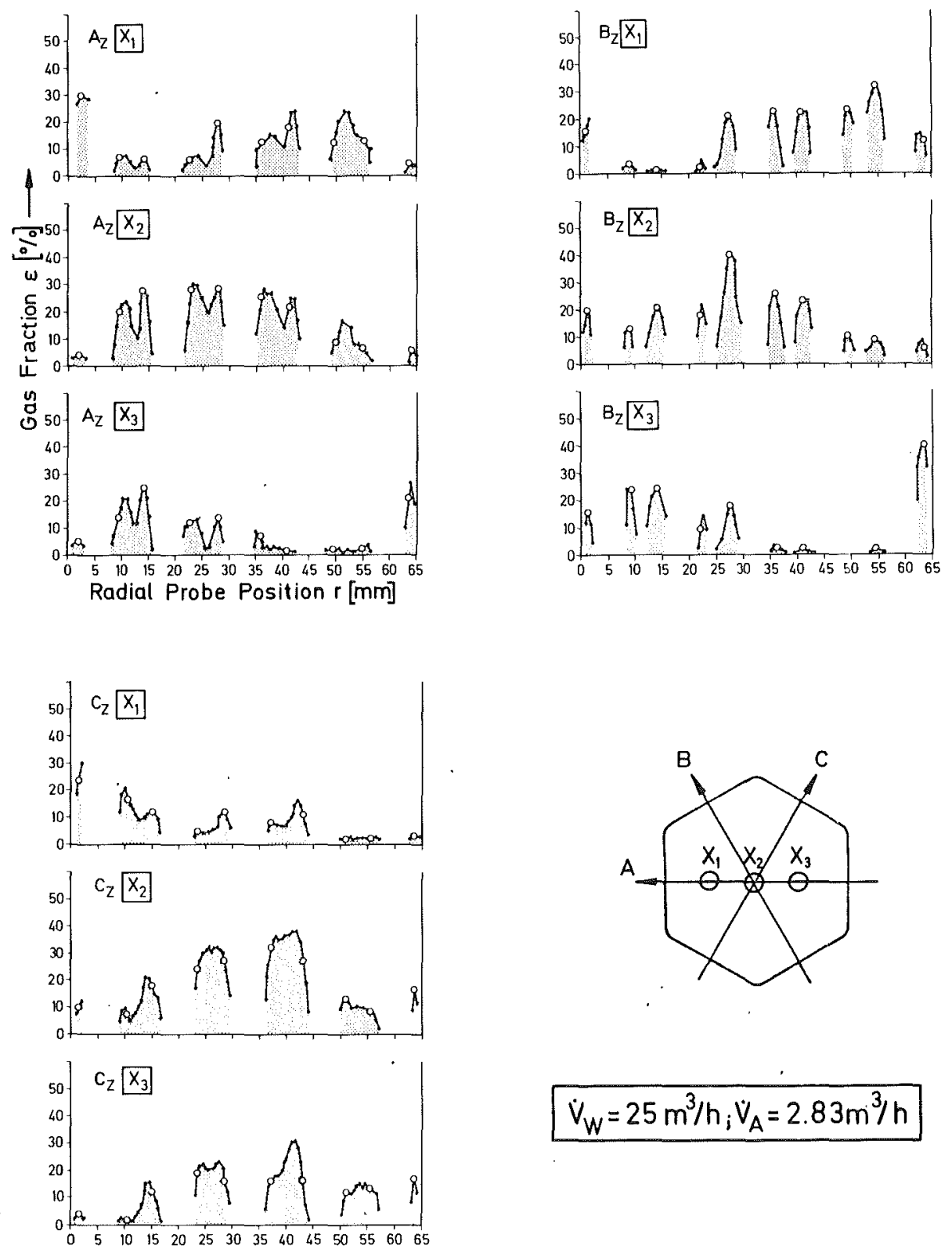

$\dot{V}_{W}=25 \mathrm{~m}^{3} / \mathrm{h}_{i} \dot{V}_{A}=2.83 \mathrm{~m}^{3} / \mathrm{h}$

Fig. 8 MEASURED GAS DISTRIBUTION AT BUNDLE OUTLET - NON-UNIFORM GAS DISTRIBUTION AT BUNDLE INLET 

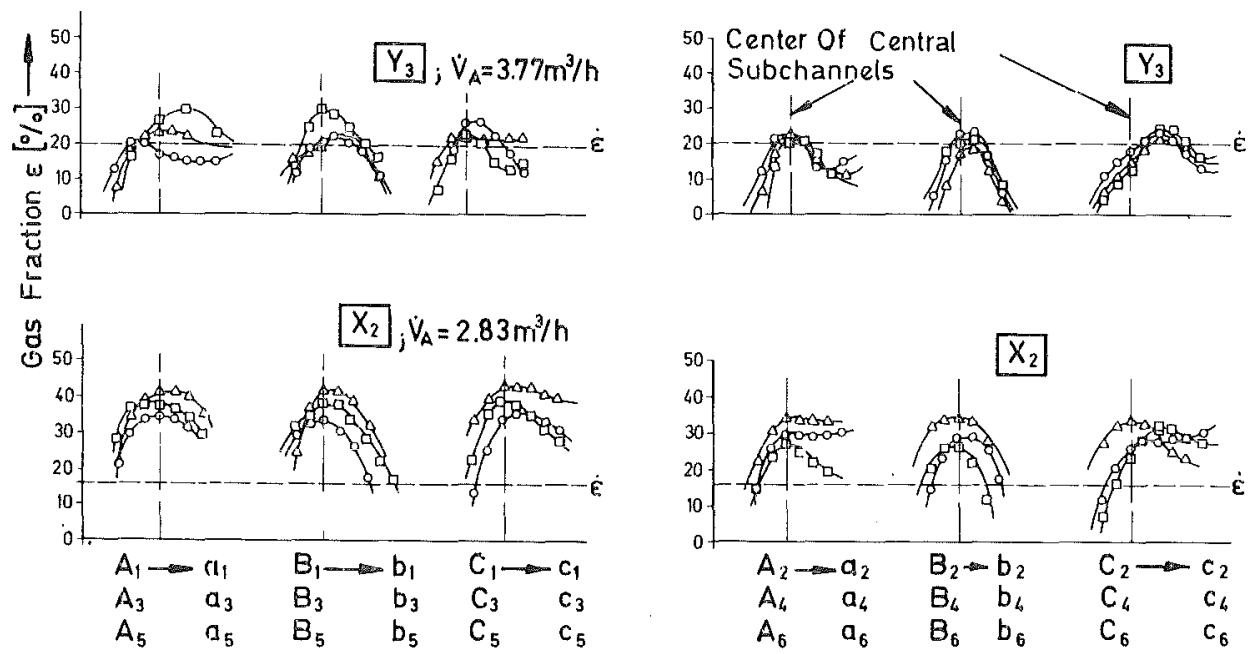

Geometrically Similar Subchannels

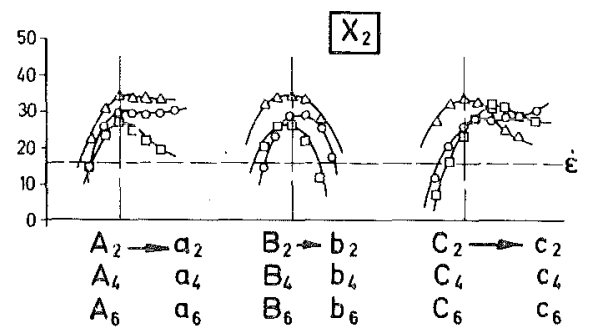

$$
\begin{array}{rl}
1-3-5 & \text { Channel } \\
2-4-6 & \Delta 2 \Delta \\
3 & 5060
\end{array}
$$
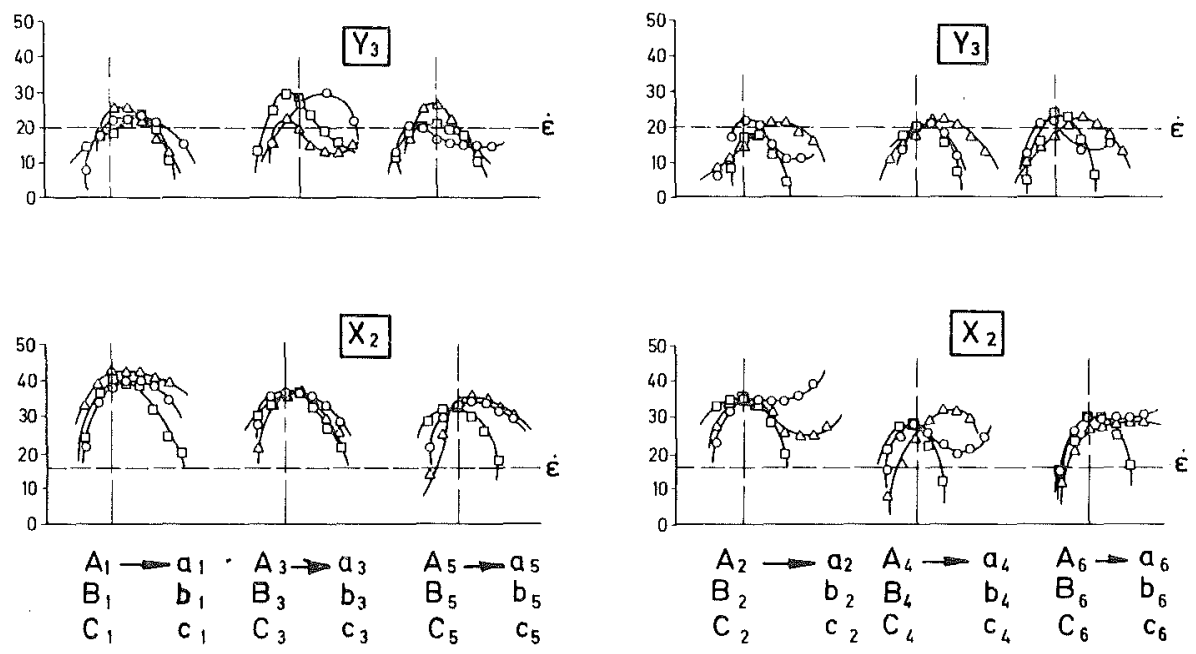

Same Channels - 3 Traverses Each

$$
\begin{array}{ll}
\text { Traverse } & A-a O \\
B & -b \square \\
C & -c \triangle
\end{array}
$$

$V_{w}=15 \mathrm{~m}^{3} / \mathrm{h}$

Fig. 9 MEASURED GAS DISTRIBUTION AT BUNDLE OUTLET - CENTRAL SUBCHANNEL

- geometrically similar subchanNels, comparable MEASURING TRAVERSES

- SAME SUBCHANNELS, 3 TRAVERSES EACH

- UNIFORM (Y) AND NON-UNIFORM (X) GAS DISTRIBUTION AT BUNDLE INLET 

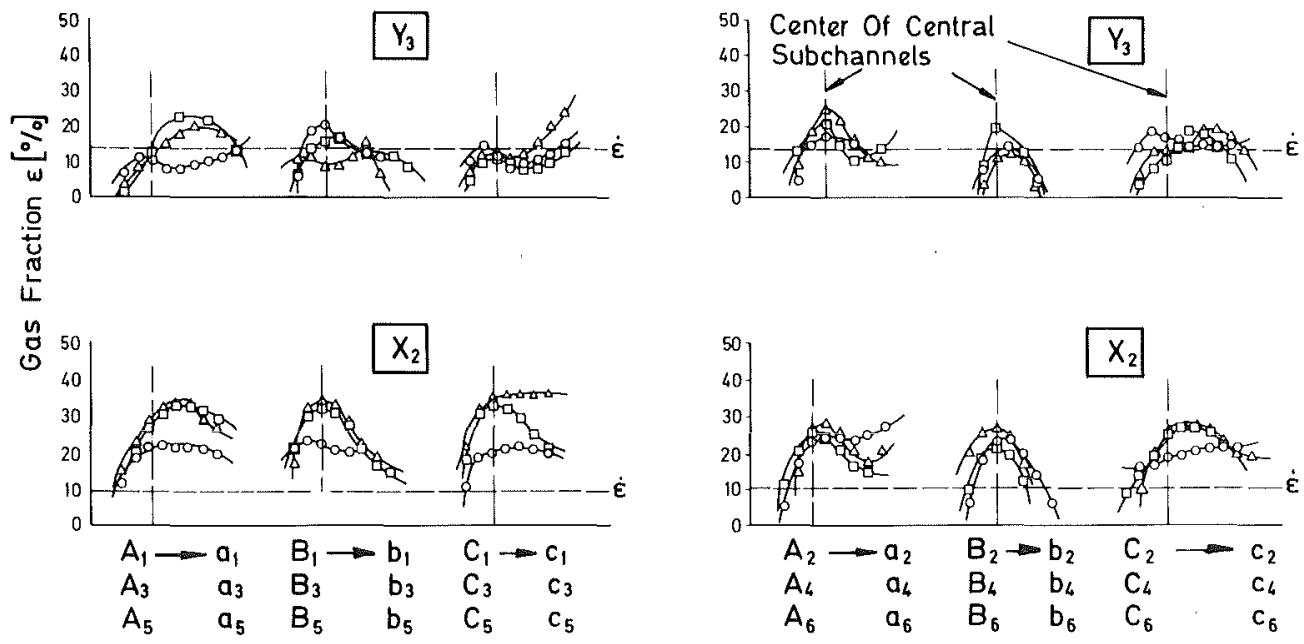

Geometrically Similar Subchannels $\begin{array}{r}1-3-5 \\ 2-4-6\end{array}$

Channel $1 \Delta 2 \Delta$

$3 \square 4 \square$
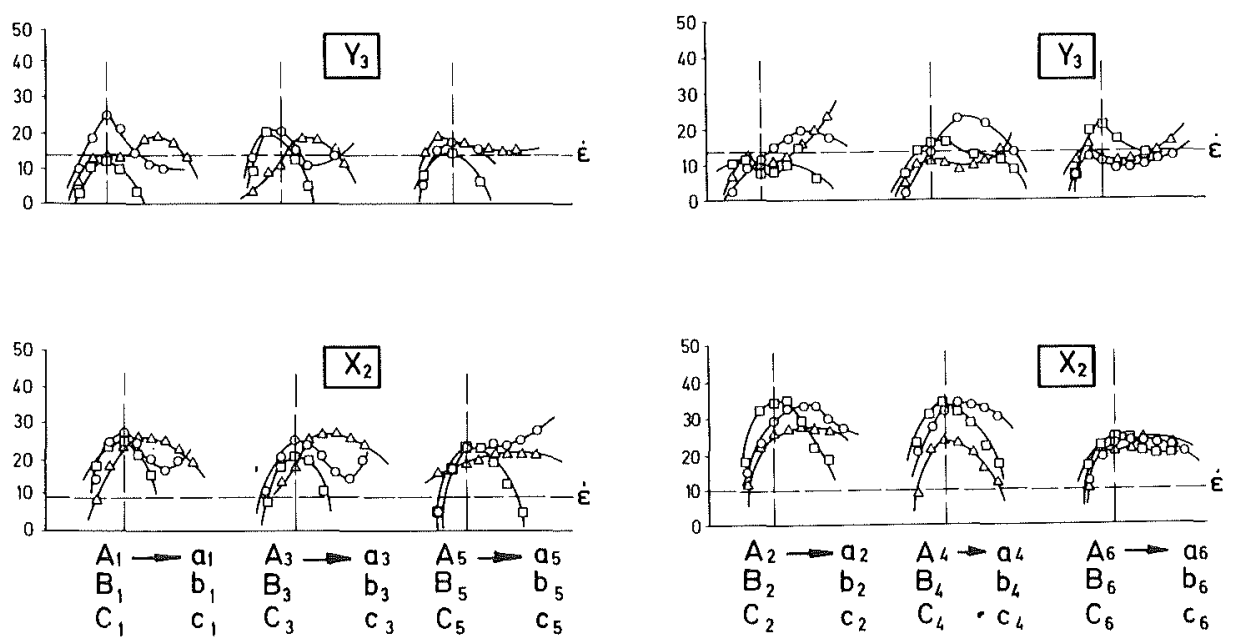

Same Channels - 3 Traverses Each

$\dot{V}_{w}=25 \mathrm{~m}^{3} / \mathrm{h}$

$$
\text { Traverse: } A-a O
$$

Fig. 10 MEASURED GAS DISTRIBUTION AT BUNDLE OUTLET - CENTRAL SUBCHANNEL

- geometrically SIMILAR SUBChaNNELS, COMPARABLE MEASURING TRAVERSES

- SAME SUBCHANNELS, 3 TRAVERSES EACH

- UNIFORM (Y) AND NON-UNIFORM (X) GAS DISTRIBUTION AT BUNDLE INLET 

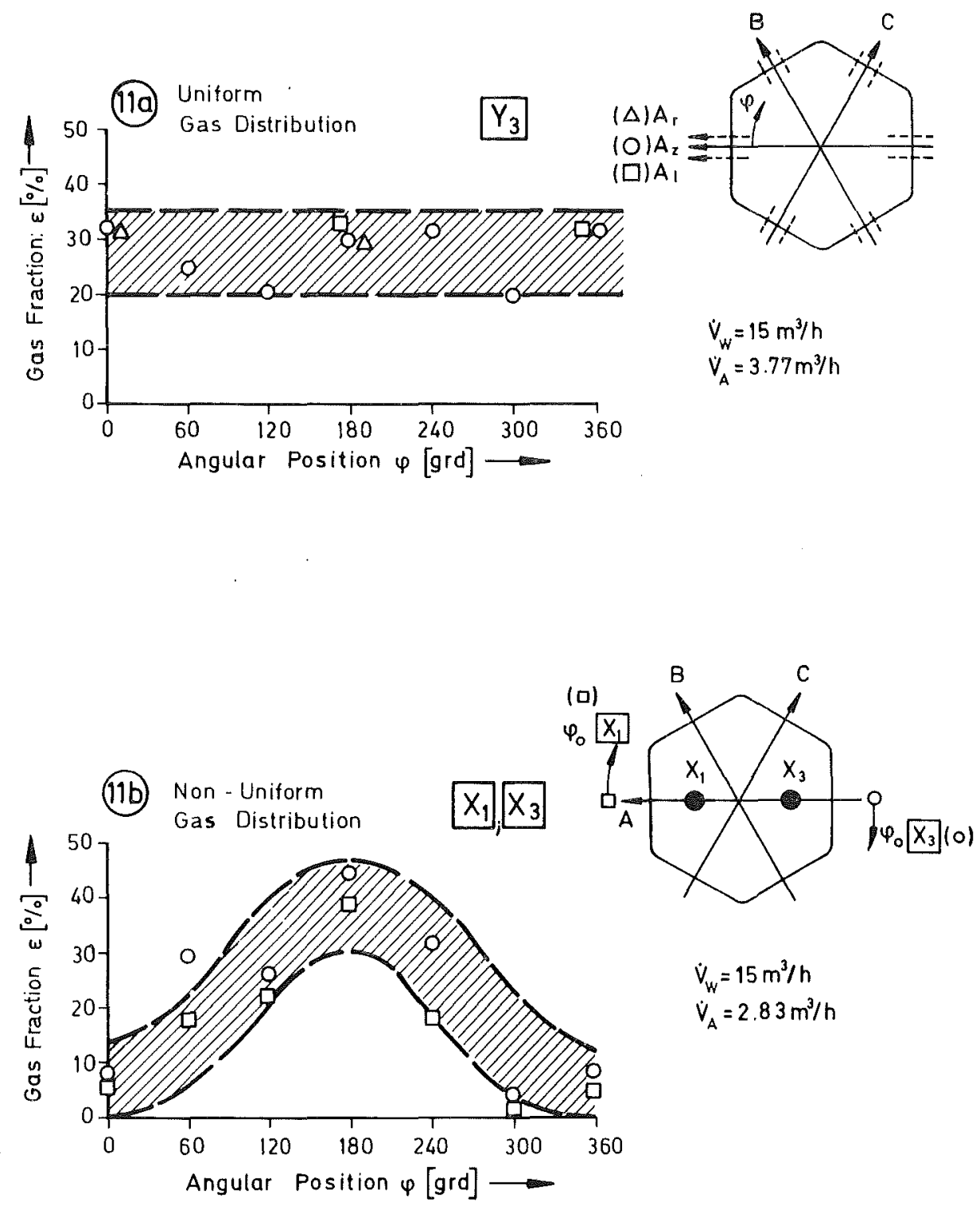

Fig. 11 MEASURED GAS DISTRIBUTION AT BUNDLE OUTLET

- WALL - SUBCHANNELS

- UNIFORM (Y) AND NON-UNIFORM (X) GAS DISTRIBUTION AT BUNDLE INLET 


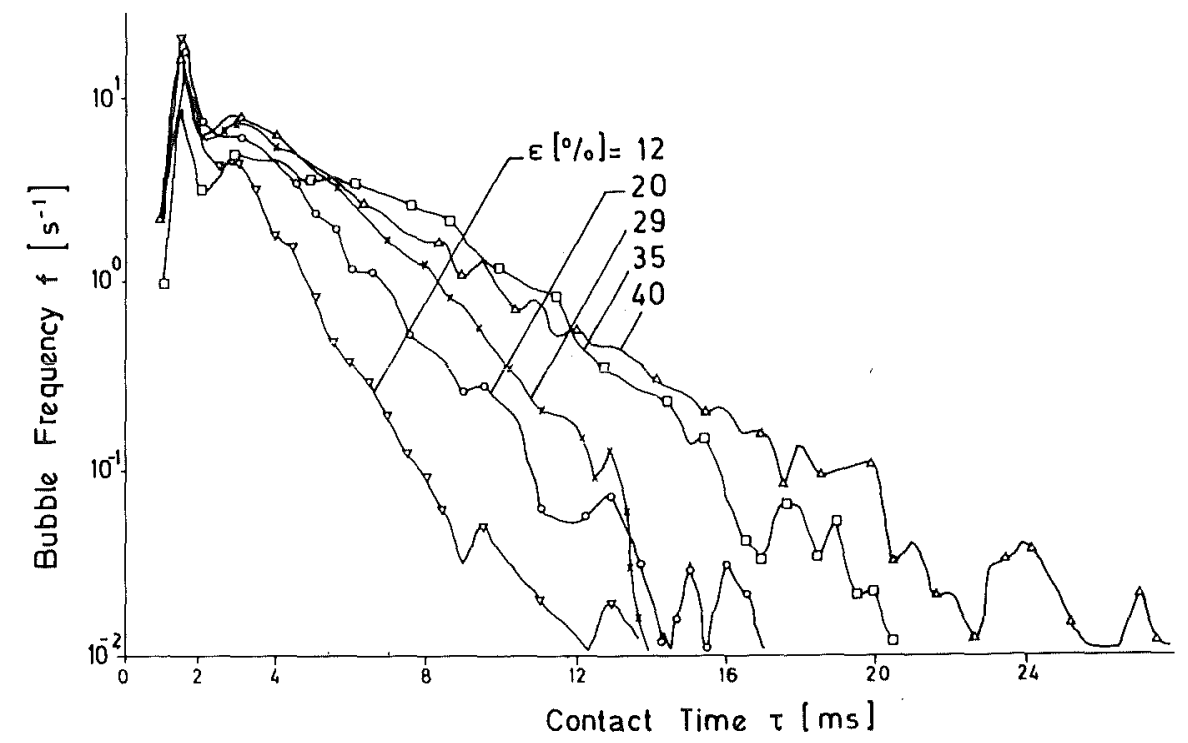

Fig. 12 BUBBLE FREQUENCY VS BUBBLE CONTACT TIME FOR DIFFERENT SUBCHANNEL GAS CONTENTS $(\varepsilon)$

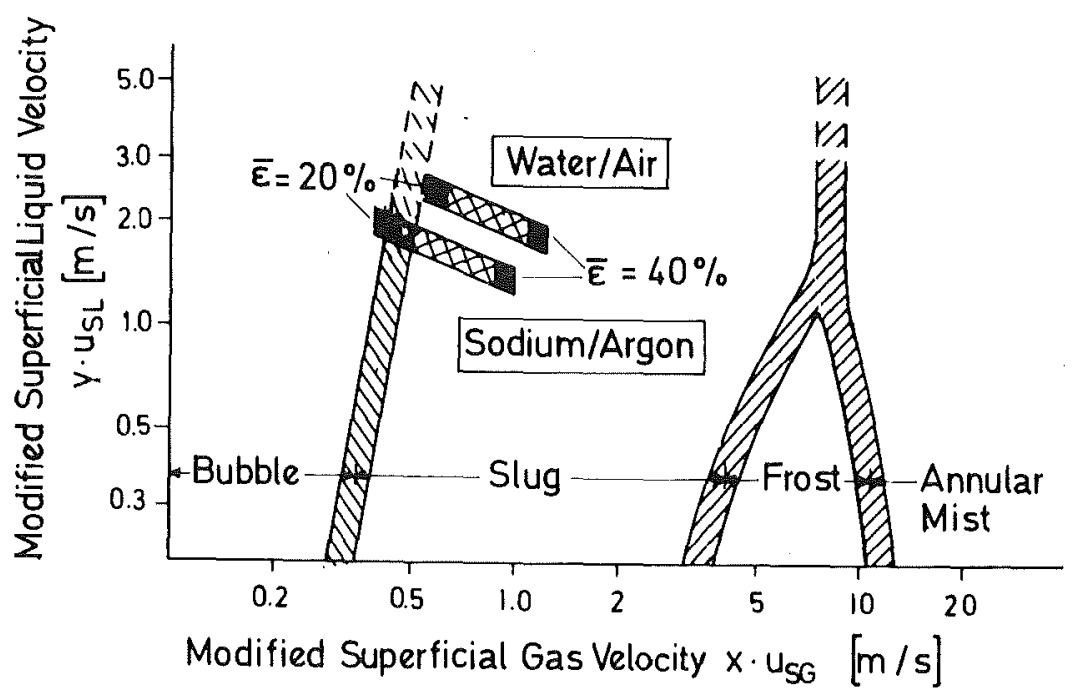

Fig. 13 GENERALIZED FLOW PATTERN MAP FOR FLOW OF LIQUID / GAS MIXTURES 


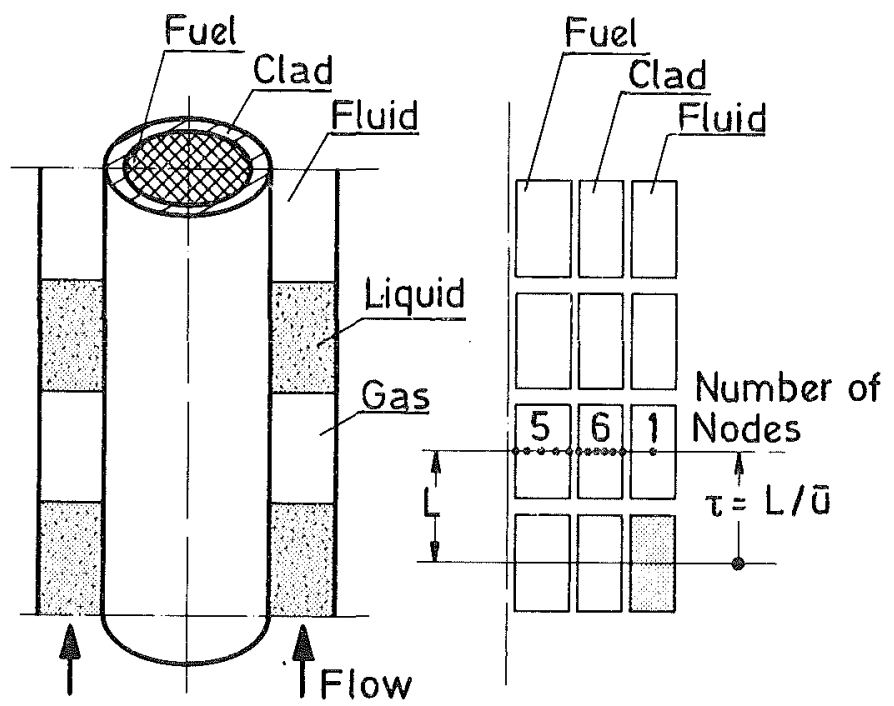

Fig. 14 DISCRETISATION OF CALCULATION MODEL (L : AXIAL NODE DISTANCE; $\bar{u}:$ FLUID VELOCITY)

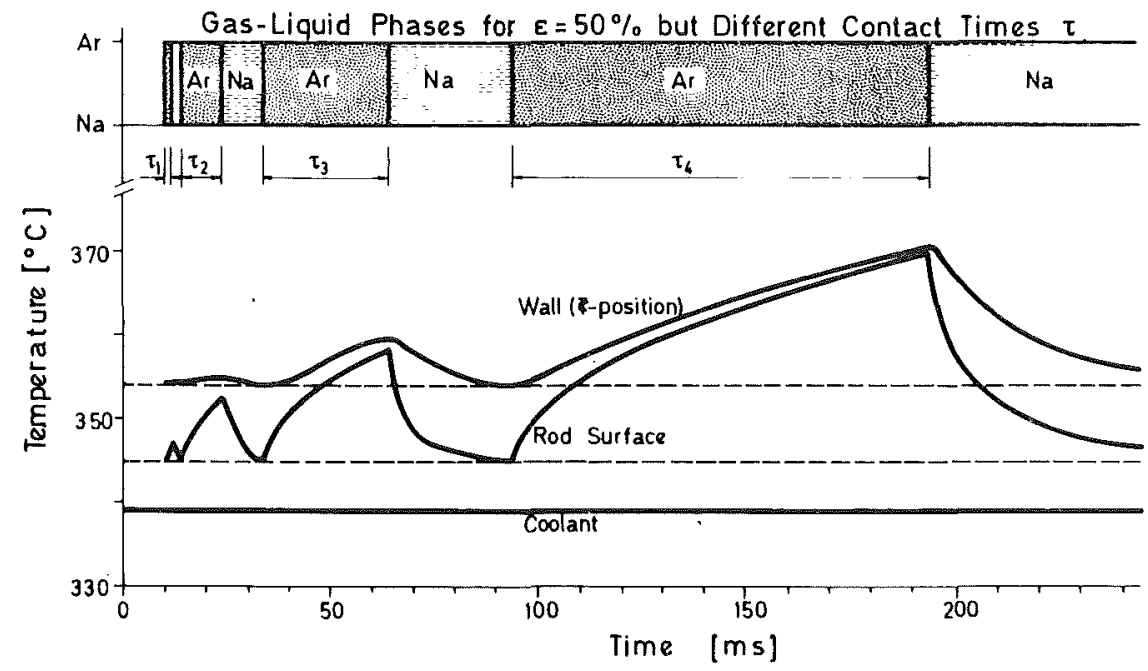

Fig. 15 LIQUID/GAS-PHASES OF DIFFERENT CONTACT TIMES AND THEIR INFLUENCES ON COOLANT-,ROD SURFACE-, AND WALLTEMPERATURES 


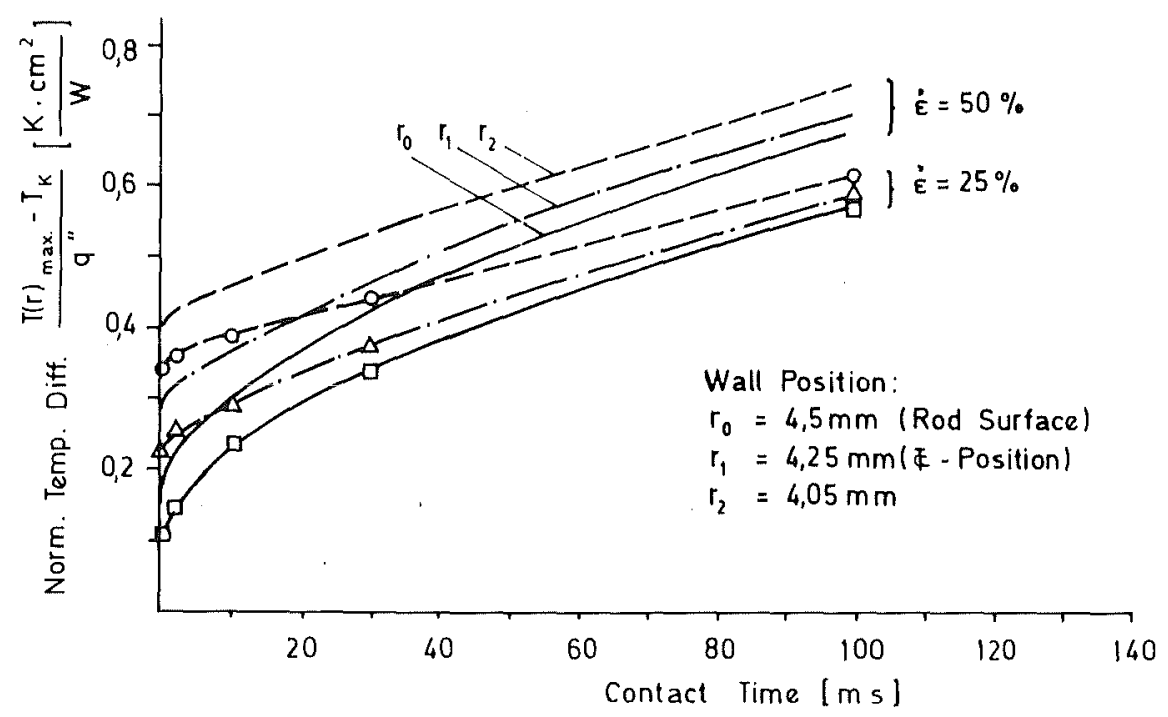

Fig. 16 NORMALIZED TEMPERATURE DIFFERENCES VS CONTACT TIME

- DIFFERENT GAS FRACTIONS

- DIFFERENT RADIAL WALL POSITIONS

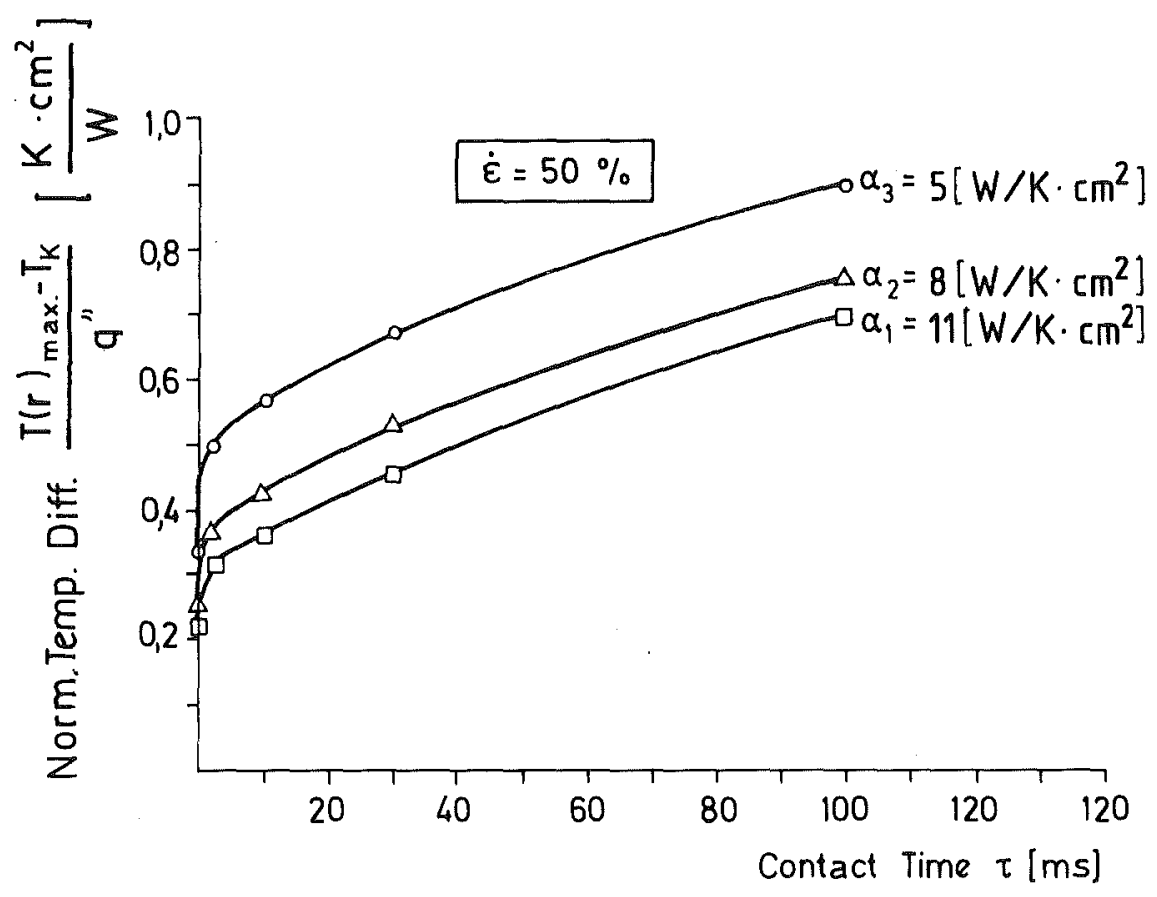

Fig. 17 NORMALIZED TEMPERATURE DIFFERENCES VS CONTACT TIME

- AT THE $₫$-POSITION $\left(r_{1}\right)$

- DIFFERENT HEAT TRANSER COEFFICIENTS 


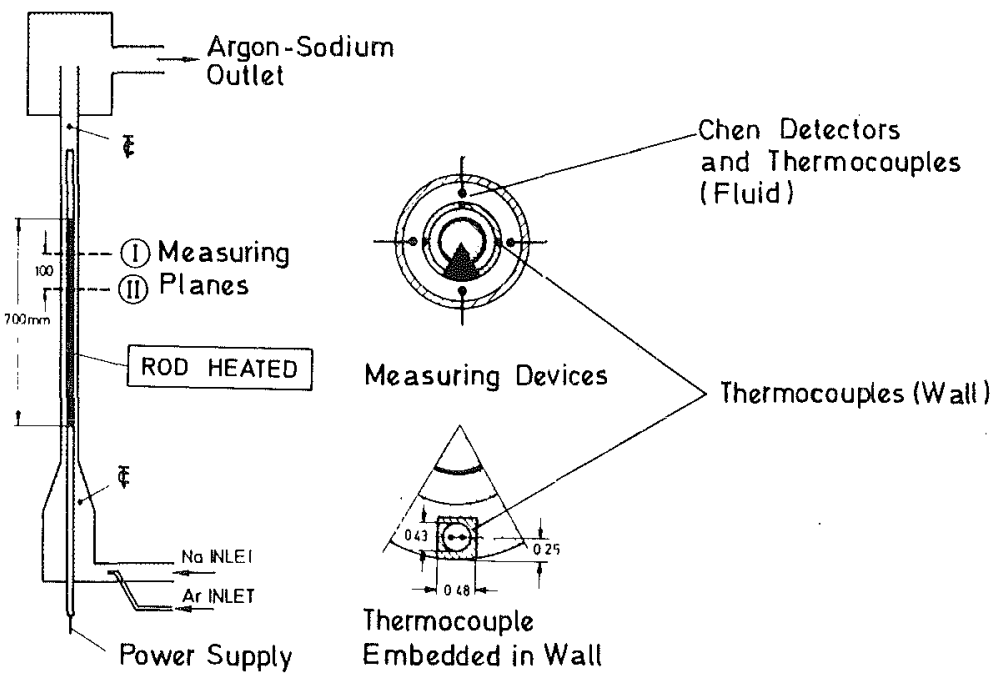

Fig. 18 TEST SECTION ANNULUS WITH HEATED ROD

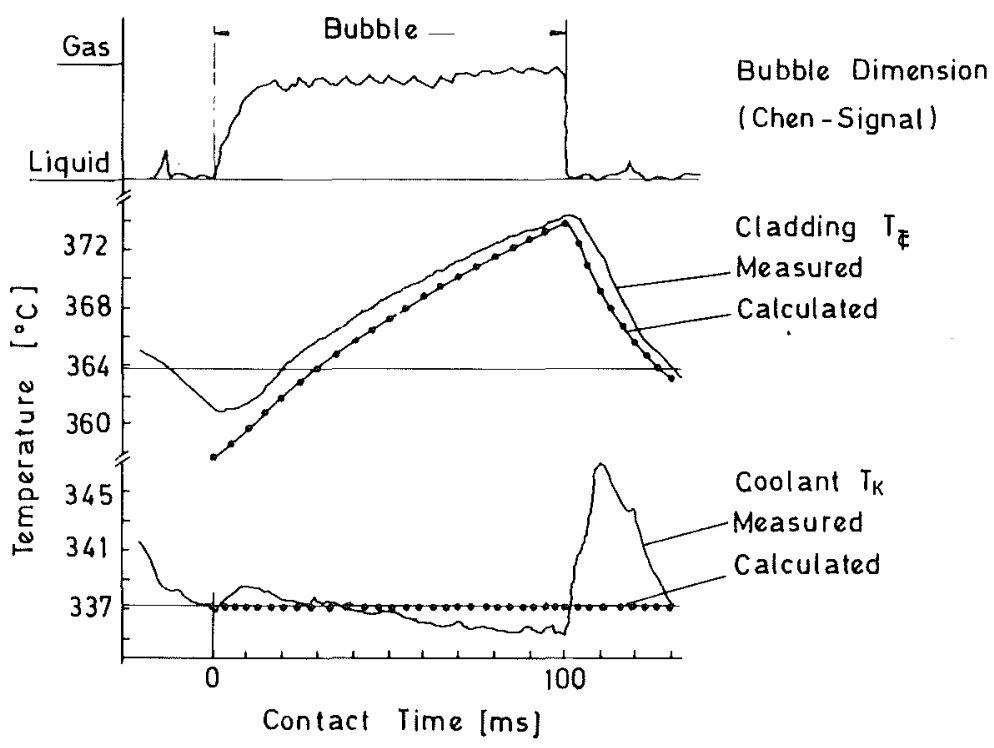

Fig. 19 TYPICAL MEASURING SIGNAL IN SODIUM FLOW 


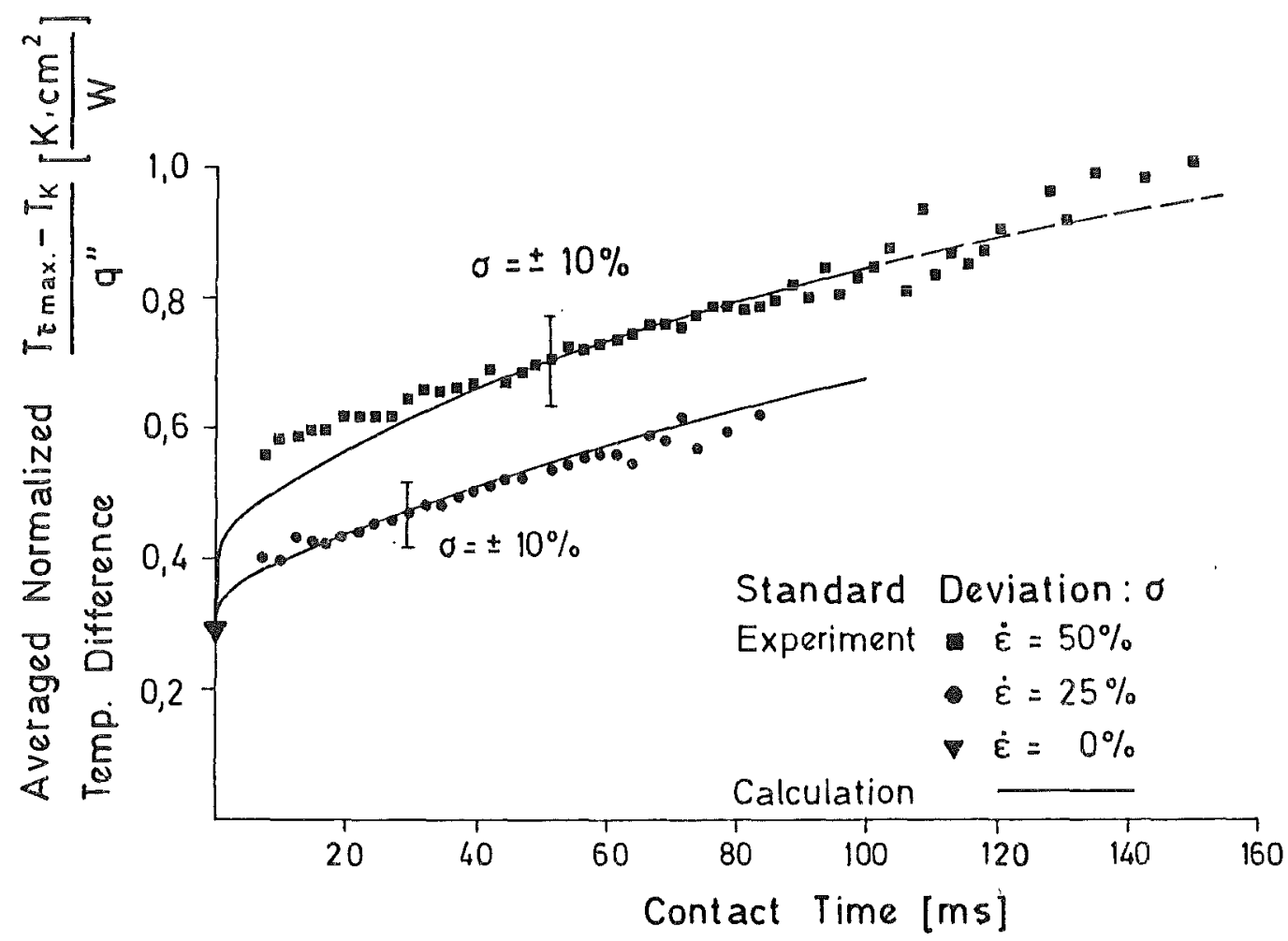

Fig. 20 AVERAGED NORMALIZED TEMPERATURE DIFFERENCE AT MEASURING POINT ( $\Phi)$ VS CONTACT TIME

- FOR VARIOUS GAS FRACTIONS IN A SODIUM FLOW 